\title{
ANÁLISIS DE LA LEGITIMIDAD DEL INTERÉS DE GRUPO EN EL ORDENAMIENTO JURÍDICO ESPAÑOL
}

\author{
The legitimacy of the group interest \\ in spanish legislation
}

\author{
Lourdes Castro Crespo \\ Graduada en Derecho económico \\ Universidad de Deusto
}

http://dx.doi.org/10.18543/ed-69(2)-2021pp305-340

\section{Resumen}

La ausencia de regulación de los grupos de sociedades de forma sistemática y global en el ordenamiento jurídico español da lugar a una serie de problemas que generan inseguridad jurídica y que se tratan de abordar en el presente trabajo. Se centra la atención en uno de esos problemas en particular: la existencia o no del interés de grupo, su posible coordinación con el interés social y los mecanismos tuitivos de los socios externos de una sociedad integrante de un grupo (que integran el llamado «conflicto de grupo»). Los argumentos para apoyar una u otra postura proceden en buena medida de las muy valiosas aportaciones doctrinales, del derecho proyectado en el Anteproyecto de Código Mercantil y de la escasa jurisprudencia hasta la fecha.

\section{Palabras claves}

Grupos de sociedades, interés de grupo, ventajas compensatorias, responsabilidad.

\section{Abstract}

The absence of a systematic and global regulation of groups of societies by Spanish legislation is a source of legal uncertainty. This thesis analyzes the concept «interest of the group», its possible coordination with the single company's interest and the protection of creditors and minor shareholders. Due to the lack of regulation regarding groups 
of companies already mentioned, the existing arguments to solve the problematic situation derive from the very valuable doctrine, from projected law and from the very scarce case law.

\section{Keywords}

Groups of companies, group interest, compensatory advantages, liability. 


\begin{abstract}
SuMARIO: I. INTRODUCCIÓN. II. Los GRUPOS DE SOCIEDADES EN EL Derecho eSPAÑol. 1. Inexistencia de un Derecho de grupos de sociedades. 2. Noción y tipos de grupos de sociedades. III. CONSECUENCIAS DE LA DEFICITARIA REGULACIÓN DE LOS GRUPOS DE SOCIEDADES. $1 . \mathrm{Mo}$ delo organizativo distinto del de la sociedad aislada. 1.1. Ejercicio de la dirección unitaria. 1.2. Mecanismos tuitivos de socios externos y acreedores. 1.2.1. Sociedad dominante como administradora de hecho. 1.2.2. Levantamiento del velo societario. 1.2.3. Deber de fidelidad del socio de control. 1.2.4. Otras aportaciones doctrinales. 2. Conflicto de intereses ¿legitimidad del interés del grupo? IV. LEGITIMIDAD DEL INTERÉS DE GRUPO EN LA JURISPRUDENCIA ESPAÑOLA A TRAVÉS DE LA TEORÍA DE LAS VENTAJAS COMPENSATORIAS. 1. Antecedentes, aplicación jurisprudencial de la teoría y acogida a nivel comunitario. 2. Deberes de los administradores. V. CRÍTICA A LA TEORÍA DE LAS VENTAJAS COMPENSATORIAS. VI. CONCLUSIONES. VII. REFERENCIAS.
\end{abstract}

\title{
I. INTRODUCCIÓN
}

La presencia en el tráfico jurídico y económico de los grupos de sociedades ha dado lugar a una serie de problemáticas que, desde un punto de vista estrictamente societario y dejando a un lado su tratamiento en otras ramas del ordenamiento, pretenden sintetizarse en el presente trabajo. Las principales cuestiones que se resolverán son: 1) si existe un interés de grupo distinto del interés social; y 2) si ese interés de grupo (en caso de que exista) es merecedor de protección en los casos en los que se contraponga al interés social de las sociedades integradas en el grupo en cuestión. Se trata de un asunto complejo, puesto que los grupos de sociedades carecen de una regulación sistemática en el ordenamiento jurídico español, por lo que las posibles soluciones vienen de la mano de la doctrina especializada y de la jurisprudencia. Precisamente esta complejidad y esta ausencia de régimen jurídico constituyen los motivos de la elección del trabajo, que pretende evidenciar la situación de inseguridad jurídica que se deriva del estado de la cuestión en el ordenamiento.

El trabajo comienza haciendo alusión a la comentada ausencia de un Derecho de grupos de sociedades en el ordenamiento jurídico y a la conveniencia de una regulación sistemática del mismo. A continuación, se define el grupo de sociedades haciendo especial hincapié en el concepto de «dirección unitaria» y se exponen los distintos tipos de grupos que pueden surgir en función de la distinta configuración de la dirección unitaria, para que sea más sencillo identificar los problemas que pueden surgir en el seno de los mismos. Tras una breve exposición de dichos problemas, se plantea al lector la pregunta clave del trabajo: ¿el interés de grupo goza de legitimidad a pesar 
de no estar reconocido legalmente? El planteamiento que cuenta con un mayor consenso doctrinal y jurisprudencial - que responde afirmativamente a la cuestión - es la teoría de las ventajas compensatorias que se analiza seguidamente, para luego introducir una crítica a la misma. Finalmente, se exponen las conclusiones que derivan de todo lo anterior.

Nótese que a pesar de que el grupo lo pueden formar otros sujetos, a lo largo del trabajo se hace referencia a los grupos de sociedades, de la misma manera que se presume en todo caso que el titular de la dirección unitaria es una sociedad (cuando en la práctica pueden serlo otro tipo de entidades o personas físicas). Ello se debe a que la reducida extensión del trabajo exige atenerse a los supuestos más habituales dentro de la amplia casuística de los grupos de empresas.

\section{LOS GRUPOS DE SOCIEDADES EN EL DERECHO ESPAÑOL}

\section{Inexistencia de un Derecho de grupos de sociedades}

Los grupos de sociedades - a pesar de su presencia en el tráfico económico - carecen de una regulación propia en el ordenamiento jurídico español, a diferencia de otros países que han optado por un tratamiento sistemático de los mismos $^{1}$. En efecto, si bien el legislador español hace continuas referencias a los grupos de sociedades, se trata de una regulación parcial, sectorial y asistemática ${ }^{2}$ en función de las necesidades de las concretas ramas del ordenamiento y que muchas veces llega a ser contradictoria ${ }^{3}$ (vid. infra apartado III.B). Es decir, las diferentes normas se limitan a proporcionar una definición del grupo a los solos efectos de que un determinado supuesto de hecho sea subsumible - $\mathrm{O}$ no- en lo regulado por ellas ${ }^{4}$. Algunos ejemplos de este fenómeno son el artículo 42 del

${ }^{1}$ Alemania fue pionera en la regulación de los grupos de sociedades con la promulgación de la Aktiengesetz (Ley de Sociedades por Acciones) de 1965, basándose en un modelo contractual como criterio delimitador del grupo. Portugal (a través de su Código de sociedades comerciales de 1986) y Brasil — entre otros - han seguido el ejemplo de Alemania, con fórmulas delimitadoras similares. Otros países como Italia (a través de la reforma del Codice Civile en 2003) han optado por un sistema orgánico, de manera que no es necesaria la concurrencia de un contrato para delimitar el grupo. Vid. FernándeZ MARKAIDA, Idoia. «Los grupos de sociedades en el derecho comparado: los dos grandes sistemas». En: Los grupos de sociedades como forma de organización empresarial. Madrid: Ed. Edersa, 2006, págs. 41-107.

2 De Arriba Fernández, María Luisa. Derecho de grupos de sociedades. Madrid: Ed. Civitas, 2004, págs. 25 y 39.

3 Embid Irujo, José Miguel. «Ante la regulación de los grupos de sociedades en España». Revista de Derecho Mercantil. 2012, n. ${ }^{\circ}$ 284, pág. 7.

${ }^{4}$ Embid Irujo, José Miguel. «La regulación de los grupos en la Propuesta de Código de Sociedades Mercantiles». En: Estudios de Derecho de sociedades y Derecho concur- 
Código de Comercio (CCom en lo sucesivo) ${ }^{5}$, el artículo 163 quinquies de la Ley del Impuesto sobre el Valor Añadido (LIVA en lo sucesivo) ${ }^{6}$, el artículo 58 de la Ley del Impuesto sobre Sociedades (LIS en lo sucesivo) 7 , o el artículo 78 de la Ley de Cooperativas (L.Coop en lo sucesivo) ${ }^{8}$.

No obstante, la ausencia de un régimen propio de grupos de sociedades no puede conducir a poner en entredicho su legitimidad como forma de organizar la empresa ${ }^{9}$, y ello por dos motivos. En primer lugar, porque el propio ordenamiento jurídico reconoce la existencia del grupo a través de las referencias legislativas a las que se hacía alusión en el párrafo precedente, sin que en ningún caso declare su ilicitud. En segundo lugar, porque la Constitución Española de $1978^{10}$ reconoce en su artículo 38 la libertad de empresa en el marco de la economía de mercado, e impone el deber a los poderes públicos de garantizar y proteger su ejercicio y la defensa de la productividad ${ }^{11}$. El problema surge, por tanto, no por la ausencia de regulación per se, sino por el desfase existente entre el Derecho de sociedades vigente y la realidad ${ }^{12}$. Así, en palabras de Paz-Ares, el tradicional Derecho de sociedades «ha sido construido tradicionalmente bajo el modelo de una sociedad independiente, con una voluntad social propia formada en el seno de sus órganos y actuando en persecución de un interés social autónomo» ${ }^{13}$.

Es evidente, por tanto, que el Derecho de sociedades tradicional — basado en una «sociedad isla» $\mathrm{o}$ «aislada»-, se contrapone con la esencia misma del grupo, en el que coexisten una pluralidad de sujetos jurídicamente autónomos, con una voluntad social supeditada a un mandato externo impuesto o

sal. Libro Homenaje al profesor Rafael García Villaverde, I (págs. 389-408). Madrid: Ed. Marcial Pons, 2007, pág. 392.

5 BOE-A-1885-6627.

${ }^{6}$ BOE-A-1992-28740.

7 BOE-A-2014-12328.

${ }^{8}$ BOE-A-1999-15681.

9 En cuanto a la legitimidad de la empresa de grupo, vid. IrÁculis Arregui, Nerea. «Interés del grupo y daño patrimonial por acatamiento de una instrucción ilegítima: responsabilidad por negligencia de los administradores de la sociedad dominada». Revista de Derecho de Sociedades, 2017, n. ${ }^{\circ} 49$, pág. 7, que opina que «el grupo goza de una legitimidad de primer grado, al preverse la licitud de su constitución, pero carece de una legitimidad de segundo grado, al omitirse toda referencia a su operatividad o funcionamiento».

${ }^{10}$ BOE-A-1978-31229.

11 Embid Irujo, José Miguel. «Pautas para el tratamiento de los grupos de sociedades en el marco de la Unión Europea». Noticias de la Unión Europea. 2006, n. ${ }^{\circ}$ 252, pág. 59.

12 Desfase que reconoce explícitamente la Sentencia del Tribunal Supremo (Sala Cuarta) de 20 de octubre de 2015, rec. 172/2014. Ref. Aranzadi, RJ 2015\5210, F.j. 4.

13 Paz-Ares Rodríguez, Cándido. «Uniones de empresas y grupos de sociedades». En: Menéndez Menéndez, Aurelio y Rojo, Ángel (dirs.). Lecciones de Derecho Mercantil (págs. 631-648). Cizur Menor: Ed. Civitas, 2019, pág. 640. 
concordado $^{14}$ (vid. infra apartado III. B). Esa dicotomía derivada de la pluralidad de empresas jurídicamente independientes y de la subordinación de las mismas a una dirección económica unitaria se conoce como «conflicto de grupo», y ante la falta de normas sustantivas que puedan solucionarlo, se han dedicado a ello la doctrina y en menor medida, la jurisprudencia ${ }^{15}$. Particularmente prolífica ha sido la jurisprudencia sobre grupos en el Derecho concursal y en el Derecho del trabajo, llegando a producir contradicciones valorativas de la figura al no existir una regulación generalizada con principios aplicables a todo el ordenamiento ${ }^{16}$. Así y en lo que respecta al Derecho del trabajo, la Sentencia del Tribunal Supremo de 3 de noviembre de 2005 dispone que: «es doctrina jurisprudencial reiterada de esta Sala de lo Social del Tribunal Supremo que el grupo de empresas a efectos laborales no es un concepto de extensión equivalente al grupo de sociedades del Derecho Mercantil $\gg{ }^{17}$. Dicha doctrina jurisprudencial fue rectificada, al establecer la Sentencia del Tribunal Supremo de 29 de mayo de 2013 que «el concepto de «grupo de empresas» ha de ser - y es - el mismo en las distintas ramas del ordenamiento jurídico, siquiera en sus diversos ámbitos - mercantil, fiscal, laboral - pueden producirse singulares consecuencias que están determinadas por diversas circunstancias añadidas $\rangle^{18}$.

En cualquier caso, la jurisprudencia sobre los grupos de sociedades relativa al Derecho concursal o laboral es insuficiente para dar respuesta al conflicto de grupo al que antes se hacía alusión, ya que para ello es preciso abordar el «núcleo duro» del derecho de grupos de sociedades: la interacción pacífica de las especialidades propias de esta singular forma de empresa con las normas e instituciones del vigente Derecho de sociedades pensado para regular sociedades aisladas ${ }^{19}$. En otras palabras, el núcleo duro del Derecho de grupos de sociedades trata al mismo tiempo de legitimar el interés del grupo y de limitar su alcance como forma de tutela de las sociedades

${ }^{14}$ De Arriba Fernández, María Luisa. Derecho de grupos de sociedades... op. cit., págs. 32 y ss.

15 Embid Irujo, José Miguel. «Ante la regulación de los grupos de sociedades en España... op. cit., pág. 6.

${ }^{16}$ Embid Irujo, José Miguel. «Ante la regulación de los grupos de sociedades en España... op. cit., pág. 3.

17 Sentencia del Tribunal Supremo (Sala Cuarta) de 3 de noviembre de 2005, rec. 3400/2004. Ref. Aranzadi, RJ 2006\1244, F.j. 3. En el mismo sentido, la Sentencia del Tribunal Supremo (Sala Cuarta) de 23 de octubre de 2012, rec. 351/2012. Ref. Aranzadi, RJ 2012\10711, F. j. 3.

18 Sentencia del Tribunal Supremo (Sala Cuarta) de 27 de mayo de 2013, rec. 78/2012. Ref. Aranzadi, RJ 2013\7656, F. j. 8.

19 Embid Irujo, José Miguel. «La aportación judicial a la construcción del derecho de

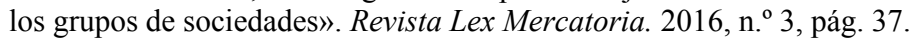


individualmente consideradas que lo integran, así como de sus socios y acreedores ${ }^{20}$, y debe ser tratado, por tanto, desde una perspectiva estrictamente societaria. Aunque no ha sido abundante la jurisprudencia que ha tratado el tema desde el punto de vista del Derecho de sociedades (y por tanto no se puede decir que exista un sólido corpus judicial sobre el grupo con esta orientación) ${ }^{21}$, cabe destacar las Sentencias del Tribunal Supremo de 11 de diciembre de $2015^{22}$ y de 12 de abril de $2007^{23}$, a las que se hará alusión a lo largo del presente trabajo.

En resumidas cuentas, es necesario seguir el ejemplo de países como Alemania, Portugal o Italia y regular los grupos de sociedades de manera sistemática, generalizada y detallada por dos motivos. Por un lado, para evitar el tratamiento del grupo de forma diversa según la óptica de cada una de las ramas del ordenamiento. Por otro lado, para regular el conflicto de grupo, de manera que se reconozca el interés del grupo y se establezcan límites claros al mismo. Dicha necesidad se hace patente en la exposición de motivos del Real Decreto Legislativo 1/2010, de 2 de julio, por el que se aprueba el texto refundido de la Ley de Sociedades de Capital (LSC en lo sucesivo) ${ }^{24}$, que declara la voluntad de provisionalidad con la que nació el texto refundido, en parte por el deber del legislador de afrontar, en el inmediato futuro, la creación de un Derecho sustantivo de los grupos de sociedades (que reconoce confinado hasta ahora «en el régimen de las cuentas consolidadas y en esas normas episódicas dispersas por el articulado»).

Sin embargo, han fracasado todos los intentos de crear un Derecho de grupos tanto a nivel europeo como nacional. En lo que al ámbito nacional se refiere (y dentro del campo del Derecho proyectado), cabe destacar la valiosa aportación que hace al respecto el Anteproyecto de Código Mercantil (ACM) aprobado por el Consejo de Ministros el 30 de mayo de 2014. A nivel europeo, no han sido pocos los intentos de las instituciones para sacar adelante un Derecho europeo en materia de grupos: en un primer momento fracasó el proyecto de la Novena Directiva europea sobre grupos de sociedades, debido a la «paralización de la armonización legislativa en materia de sociedades

${ }^{20}$ Embid Irujo, José Miguel. «El derecho de los grupos de sociedades: entre las medidas de tutela y la organización de la empresa policorporativa», Revista de Derecho Mercantil. 2017, n. ${ }^{\circ} 304$ (versión electrónica).

${ }^{21}$ Embid Irujo, José Miguel. «Interés del grupo y ventajas compensatorias. Comentario de la sentencia del Tribunal Supremo (sala primera) de 11 de diciembre de 2015», Revista de Derecho Mercantil. 2016, n. 300 (versión electrónica).

${ }^{22}$ Sentencia del Tribunal Supremo (Sala Primera) n. ${ }^{\circ}$ 695/2015, de 11 de diciembre de 2015. Ref. Aranzadi, RJ 2015\5440.

${ }^{23}$ Sentencia del Tribunal Supremo (Sala Primera) n. ${ }^{\circ} 400 / 2007$, de 12 de abril de 2007, Ref. Aranzadi, RJ 2007\2410.

${ }^{24}$ BOE-A-2010-10544. 
mercantiles de capital, la subsidiariedad de la legislación europea frente a la nacional, y la competencia de los ordenamientos jurídicos como sustitutivo de la convergencia normativa ${ }^{25}$, en opinión de Embid Irujo. Tras el fracaso de la Novena Directiva, expertos en la materia de distintas partes de la Unión Europea (UE) elaboraron un proyecto de naturaleza privada al margen de las instituciones de la UE en el denominado Forum Europaeum. La propuesta contenida en el proyecto se aleja de la voluntad uniformadora y sistemática de la Novena Directiva, y trata de lograr un consenso en torno al núcleo duro de la regulación de los grupos de sociedades en Europa - la «filosofía de la regulación ${ }^{26}$ - . De lo que se trata es de crear normas que faciliten y posibiliten el funcionamiento normal de los grupos, más que de crear normas restrictivas o prohibitivas para crear así un equal playing field entre todos los Estados miembros ${ }^{27}$. Sobre la base del Forum Europaeum se elabora el Informe Winter por un equipo de juristas europeos, que aboga, asimismo, por un Derecho europeo de grupos reducido basado en planteamientos comunes. Ni el Forum Europaeum ni el Informe Winter han producido el efecto de impulsar a las instituciones europeas a elaborar una propuesta normativa, pero es importante a este respecto mencionar el Informe del Grupo de Reflexión sobre el futuro del Derecho europeo de sociedades (Report of the Reflection Group on the Future of EU Company Law) elaborado por la Comisión Europea en 2010 en el que se reconoce que sería beneficioso adoptar una recomendación que reconozca el interés del grupo en el marco de la Unión Europea. Más recientes son las propuestas contenidas en el Informal Company Law Expert Group de 2016: Report on the recognition of the interest of the group (ICLEG), en el informe del European Company Law Experts de 2016: A proposal for reforming group law in the European Union Comparative observations on the way forward (ECLE) y en el European Model Company Act de 2017 (EMCA), todas ellas elaboradas por grupos de expertos.

\section{Noción y tipos de grupos de sociedades}

Se ha indicado previamente que no existe en el ordenamiento jurídico español un concepto universal de grupo de sociedades. De hecho, es frecuente que se den contradicciones entre las distintas disposiciones normativas a este

${ }^{25}$ Embid Irujo, José Miguel. «El significado jurídico de los grupos de sociedades. La corporate governance». Ekonomiaz. 2008, n. ${ }^{\circ}$ 68, pág. 89.

${ }^{26}$ Embid Irujo, José Miguel. «Pautas para el tratamiento de los grupos de sociedades en el marco de la Unión Europea... op. cit., pág. 60.

27 Embid Irujo, José Miguel. «A la búsqueda de un Derecho de grupos en Europa». Gaceta jurídica de la Unión Europea y de la competencia. 2004, n. ${ }^{\circ} 231$, pág. 40. 
respecto. Por ejemplo, a pesar de que tanto para el CCom (artículo 42) como para la LIS (artículo 58), el elemento esencial para la existencia de un grupo es el control o dominio que una sociedad ejerce sobre otras, sendas leyes utilizan criterios distintos para determinar cuándo se produce ese control o dominio (un sistema de presunciones y una participación mínima en el capital social, respectivamente). No obstante y desde una perspectiva del Derecho mercantil, resulta pacífico considerar que la definición del grupo del artículo 42 del CCom trasciende del mero supuesto de hecho que regula (la consolidación contable) y constituye una importante referencia del Derecho sobre gru$\operatorname{pos}^{28}$. Ello se debe a la remisión que hacen a dicho artículo diferentes normas en el ámbito mercantil. En efecto, tanto la Ley del Mercado de Valores (LMV en lo sucesivo $)^{29}$ en su artículo 5 como la LSC en su artículo 18 se remiten al artículo 42 CCom, a los efectos de determinar qué se entiende por grupo en cada una de dichas leyes.

Como se adelantaba, para el artículo 42 CCom existe un grupo «cuando una sociedad ostente o pueda ostentar, directa o indirectamente, el control de otra u otras». A continuación, establece una presunción de control cuando una sociedad — que se calificará como dominante - se encuentre en relación con otra sociedad — que se calificará como dependiente — en alguna de las siguientes situaciones: posea la mayoría de los derechos de voto; tenga la facultad de nombrar o destituir a la mayoría de los miembros del órgano de administración; pueda disponer, en virtud de acuerdos celebrados con terceros, de la mayoría de los derechos de voto y/o haya designado con sus votos a la mayoría de los miembros del órgano de administración ${ }^{30}$. A pesar de la relevancia práctica de este artículo por las remisiones que hacen al mismo normas tan importantes en el Derecho mercantil como la LSC, ha sido duramente criticado tras su reforma por la Ley 16/2007, de 4 de julio, de reforma y adaptación de la legislación mercantil en materia contable para su armonización internacional con base en la normativa de la Unión Europea ${ }^{31}$. Ello es

${ }^{28}$ Embid Irujo, José Miguel. «Un paso adelante y varios atrás: sobre las vicisitudes recientes del concepto legislativo del grupo en el ordenamiento español». Revista de Derecho de Sociedades. 2008, n. ${ }^{\circ} 30$, pág. 6.

${ }^{29}$ BOE-A-2015-11435.

${ }^{30}$ El ACM aprobado por el Consejo de Ministros el 30 de mayo de 2014 introduce otras dos situaciones cuya concurrencia dará lugar a la presunción de existencia de grupo en su artículo 291-3: «cuando una sociedad haya incluido en la denominación elementos significativos de la denominación o del anagrama de otra sociedad o de signo distintivo notorio o registrado a nombre de ésta o de cualquier otra sociedad perteneciente al grupo» y «cuando una sociedad haya hecho constar en la documentación o en cualquier clase de publicidad la perteneciente de la misma al grupo». La regulación sobre grupos se mantiene invariable en la actualización de la propuesta de Anteproyecto de marzo de 2018.

31 BOE-A-2007-13023. 
así porque gran parte de la doctrina considera más adecuado sustituir la noción de «control» o «dominio» por la de «dirección unitaria», «unidad de decisión» 0 «dirección económica común» como verdadero elemento delimitador del grupo, volviendo así a la redacción del artículo 42 CCom previo a la reforma mencionada ${ }^{32}$. Por eso, Paz-Ares define acertadamente el grupo como «la organización de varias sociedades jurídicamente independientes bajo una dirección económica unitaria» $\rangle^{33}$. Sí existen, en cambio, otras normas en el ordenamiento jurídico español que hacen referencia a esa dirección unitaria. Son paradigmáticos en este sentido el artículo 78 L.Coop., que entiende como grupo (cooperativo) «el conjunto formado por varias sociedades cooperativas, cualquiera que sea su clase, y la entidad cabeza de grupo que ejercita facultades o emite instrucciones de obligado cumplimiento para las cooperativas agrupadas, de forma que se produce una unidad de decisión en el ámbito de dichas facultades», y el artículo 7.2 de la Ley de Defensa de la Competencia (LDC en lo sucesivo) ${ }^{34}$, al hablar de «ejercer una influencia decisiva sobre una empresa».

La diferencia entre dependencia, control o dominio y dirección unitaria no es baladí. Esta última supone una «planificación económica del colectivo por parte de la matriz y determina las líneas de actividad de cada sociedad agrupada y su participación en la consecución del interés del grupo ${ }^{35}$ (De Arriba Fernández). Se puede definir, asimismo, como la facultad de la entidad cabeza de grupo de impartir instrucciones de obligado cumplimiento ${ }^{36}$, convirtiendo así al grupo en la forma de vinculación empresarial más intensa, más allá de la cual solo queda la fusión ${ }^{37}$. La dependencia, por su parte, no es más que la mera posibilidad de la sociedad dominante de ejercer una

${ }^{32}$ En este sentido DE Arriba Fernández, María Luisa. Derecho de grupos de sociedades... op. cit., pág. 84, PAZ-Ares RodríGuez, Cándido. «Uniones de empresas y grupos de sociedades»... op. cit., pág. 636, EmbiD Irujo, José Miguel, «Interés del grupo y ventajas compensatorias... op. cit (versión electrónica) y CASTRO De LunA, Manuel José. «Hacia un modelo contractual del concepto de grupo de sociedades». Revista Quincena Fiscal. 2015, n. ${ }^{\circ}$ 20, pág. 3.

33 Paz-Ares Rodríguez, Cándido. «Uniones de empresas y grupos de sociedades»... op. cit., pág. 636 .

34 BOE-A-2007-12946.

35 De Arriba Fernández, María Luisa. Derecho de grupos de sociedades... op. cit., pág. 201.

36 Vid. artículo 78.1 L.Coop.

37 De Arriba Fernández, María Luisa. Derecho de grupos de sociedades... op. cit., págs. 79 y ss. En contra, el profesor Paz-Ares, que considera que las instrucciones de la sociedad matriz no pueden ser consideradas como de obligado cumplimiento para los administradores de la filial debido al papel de gatekeepers de los intereses de esta. Vid. PAz-ARes RodríGuez, Cándido. ¿Derecho común o derecho especial de grupos? Esa es la cuestión. Pamplona: Ed. Civitas, 2019, págs. 58 y ss. 
influencia sobre la dominada (o dominadas). Es decir, el control de otras sociedades puede constituir un medio para alcanzar la dirección unitaria - el «origen de la dirección unitaria» del que se hablará a continuación-, pero no puede identificarse automáticamente con una dirección económica común. En este mismo sentido se pronuncia la Audiencia Provincial de Vizcaya en su Sentencia de 13 de junio de 2002, al considerar como notas delimitadoras del concepto de grupo: «1) Pluralidad de empresas independientes; 2) Instrumento de obtención del poder de dirección; en su mayoría se comporta como elemento de control sin olvidar otras formas (...) y 3 ) La dirección unitaria $\rangle^{38}$.

Ahora bien, la dirección unitaria se puede configurar de muy diversas maneras, dando lugar a distintos tipos de grupos. Así, se puede realizar una primera clasificación de grupos en función del instrumento de creación de la dirección unitaria, dando lugar a grupos de base contractual, personal o financiera o societaria. En estos últimos, la dirección unitaria tiene su origen en la participación de la matriz en el capital de las filiales ${ }^{39}$. En cuanto a los grupos de base contractual, la dirección unitaria se origina por medio de un contrato entre las entidades agrupadas, dejando un amplio margen a la autonomía de la voluntad, siendo así que el contrato mismo determinará si se trata de un grupo por coordinación o por subordinación (en cuyo caso se tratará de un contrato de dominación), y regulará los límites del ejercicio de la dirección unitaria a efectos de proteger a los acreedores y socios externos de las sociedades del grupo. Por último, los grupos de base personal tienen su origen en la identidad personal de quienes desempeñan cargos de administradores en las distintas sociedades del grupo ${ }^{40}$.

Una segunda distinción de grupo se puede realizar en función de la concurrencia $-\mathrm{O}$ no- de un elemento de dependencia entre los miembros del grupo. Si se da dicho elemento - o lo que es lo mismo, una relación de control de la sociedad matriz (en este caso, dominante) sobre la filial (en este caso, dominada) - , se trata de un grupo vertical, de estructura jerárquica o por subordinación. En otro caso, será un grupo horizontal, de estructura paritaria o por coordinación. Si bien los instrumentos de creación de la dirección unitaria han sido convenientemente analizados en el párrafo precedente, su adecuación a los grupos de estructura paritaria requiere cierta matización. En

${ }^{38}$ Sentencia de la Audiencia Provincial de Vizcaya (Sección $3^{a}$ ) n. ${ }^{\text {3 }}$ 311/2002, de 13 de junio de 2002, Ref. Aranzadi, JUR 2002\211271. F. j. 2.

39 La participación en el capital de las filiales puede derivar en el ejercicio de una efectiva dirección unitaria si permite a la dominante (se hablaría de control en este caso) obtener la mayoría de los derechos de voto en la Junta General, así como nombrar a la mayor parte del Consejo de Administración.

${ }^{40}$ Fuentes Naharro, Mónica, Grupos de sociedades y protección de acreedores (una perspectiva societaria). Cizur Menor: Ed. Aranzadi, 2007, págs. 50 y ss. 
este tipo de grupos en los que no media una situación de dependencia o control es habitual la creación de un contrato de grupo, las reuniones periódicas de los administradores de las entidades agrupadas a efectos de fijar la dirección económica común, e incluso la creación de una sociedad ad hoc encargada de ejercer la dirección unitaria (que actuará de sociedad matriz, no así de dominante $)^{41}$.

En efecto, en los grupos horizontales la dirección unitaria no se impone desde la matriz, sino que todas las sociedades participan en la dirección económica común de manera igualitaria y coordinada ${ }^{42}$. Es por ello que este tipo de grupos se presenta como la forma idónea de inclusión de todo tipo de personas jurídicas. Si bien no parece haber problema en que formas jurídicas distintas de las sociedades de capital (o incluso personas físicas) integren un grupo de estructura vertical como dominantes, su integración como dominadas sí puede colisionar con la naturaleza misma de dichas entidades. Este es el caso, por ejemplo, de las cooperativas - en las que el principio democrático en el que se inspiran es incompatible con el hecho de hallarse supeditadas a la dirección económica de otra sociedad-o de las fundaciones - en las que parece difícil compaginar el fin de interés general que deben perseguir con el interés del grupo en su conjunto ${ }^{43}$ Como se puede fácilmente observar, la definición de grupo del artículo 42 CCom únicamente comprende a los grupos por subordinación al exigir una relación de dependencia. Por contra, el ACM introduce el concepto de dirección unitaria, y entiende que existe un grupo - además de cuando se da una situación de control de una misma persona natural o jurídica sobre otra y otras - «cuando dos o más sociedades independientes actúen coordinadamente entre sí bajo una dirección única por virtud de pactos o contratos entre ellas» (artículo 291-1), por lo que no excluye a los grupos por coordinación. Además, hace referencia expresa a los mismos en el artículo 291-4, al disponer que las normas sobre grupos serán aplicables, en lo que proceda, «a aquellos grupos en los que dos o más sociedades independientes actúen coordinadamente entre sí bajo un poder de dirección unitario y común».

Una tercera distinción de los grupos de empresas basada en el origen de la dirección unitaria es la que da lugar a los grupos de hecho y de Derecho. En estos últimos, la dirección unitaria que caracteriza al grupo se crea por

${ }^{41}$ Fuentes Naharro, Mónica. Grupos de sociedades y protección de acreedores (una perspectiva societaria)... op. cit., pág. 105 y 106.

${ }^{42}$ De Arriba Fernández, María Luisa. Derecho de grupos de sociedades... op. cit., págs. 97 y 333.

${ }^{43}$ Embid Irujo, José Miguel. «Ante la regulación de los grupos de sociedades en España»... op. cit., pág. 13. 
medio de los cauces jurídicos establecidos al efecto, mientras que en los primeros son circunstancias diversas las que pueden dar lugar al origen del grupo (las presunciones previstas en el artículo $42 \mathrm{CCom}$, los cauces comunes de creación de grupos anteriormente mencionados, etc.). Como se ha reiterado en repetidas ocasiones, en España no hay un régimen jurídico específico para los grupos de empresas, por lo que carece de sentido hablar de grupos de Derecho (excepción hecha al grupo cooperativo, regulado en el artículo 78 L.Coop. $)^{44}$.

Por otro lado, el distinto alcance de la dirección unitaria puede dar lugar a grupos más o menos centralizados, en función del grado de autonomía empresarial de las entidades sometidas a la unidad de decisión, de manera que el grupo será más centralizado cuantas más facultades se atribuyan a la entidad que dirige el grupo y menos libertad empresarial corresponda a las filiales. Ahora bien, el margen de autonomía en el ejercicio de la actividad empresarial debe estar sujeto a un límite por debajo del cual no se puede hablar ya de grupo, puesto que se desvirtúa el concepto de dirección económica común (ni siquiera como grupo descentralizado). Los partidarios de un concepto estricto del grupo fijan ese límite en el desarrollo, por parte de la entidad matriz, de una política de financiación común para todas las entidades que conforman el grupo ${ }^{45}$. Este requisito mínimo se hace patente en el varias veces mencionado artículo 42 CCom. En efecto, si se considera que el grupo requiere, al menos, la planificación y control del sector financiero, es razonable exigir la elaboración de unas cuentas anuales consolidadas del conjunto del grupo ${ }^{46}$. También es representativo del concepto estricto de grupo el artículo 163 quinquies de la LIVA, que requiere que la entidad dominante y sus dependientes «se hallen firmemente vinculadas entre sí en los órdenes financiero, económico y de organización». El concepto amplio, por contra, sostiene que la dirección unitaria debe manifestarse sobre cualquiera de los sectores empresariales fundamentales. Este parece ser el punto de vista del artículo 78 de la Ley de Cooperativas, que no restringe las facultades que debe ejercer la entidad cabeza del grupo ${ }^{47}$.

${ }^{44}$ De Arriba Fernández, María Luisa. Derecho de grupos de sociedades... op. cit., págs. 94 y 95 .

45 Embid Irujo, José Miguel. «Ante la regulación de los grupos de sociedades en España»... op. cit., pág. 16. En el mismo sentido, PAZ-ARES RODRÍGUEZ, Cándido. «Uniones de empresas y grupos de sociedades»... op. cit., pág. 636.

46 De Arriba FernándeZ, María Luisa. Derecho de grupos de sociedades... op. cit., págs. 207 y ss.

${ }^{47}$ Embid Irujo, José Miguel. «Ante la regulación de los grupos de sociedades en España»... op. cit., pág. 16. 


\section{CONSECUENCIAS DE LA DEFICITARIA REGULACIÓN DE LOS GRUPOS DE SOCIEDADES}

\section{Modelo organizativo distinto del de la sociedad aislada}

\subsection{Ejercicio de la dirección unitaria}

Ya se ha aclarado que el grupo de sociedades es una forma de organización empresarial legítima, cuya particularidad radica en la unidad económica del conjunto y en la independencia jurídica de cada una de las sociedades que lo integran. Precisamente este último elemento - la independencia jurídica - supone que de cara a terceros, la sociedad integrada en un grupo ofrece una apariencia de normalidad organizativa, ya que aparentemente nada la diferencia de una «sociedad isla» (ambas tienen los mismos deberes contables, registrales, se gobiernan por los mismos órganos: junta general y órgano de administración...). Sin embargo, la realidad interna de la sociedad integrada en un grupo es bien distinta: como consecuencia de la política económica a la que se ha hecho referencia con anterioridad, los grupos de sociedades actúan en consonancia con una dirección unitaria común, por lo que el órgano o la sociedad (matriz) que ostente dicha dirección unitaria será quien defina las políticas que deberá seguir cada sociedad agrupada ${ }^{48}$. Siendo lo más habitual que sea una sociedad (matriz) la encargada de ejercer la dirección unitaria, será su órgano de administración - como órgano gestor y representante de la sociedad - el encargado de fijar en la práctica la política económica común y de dictar las instrucciones a los órganos de administración de las sociedades dependientes ${ }^{49}$ (que serán más o menos frecuentes y permitirán un mayor o menor margen de discrecionalidad empresarial en función de si se trata de un grupo centralizado o descentralizado). Todo ello es aún más acusado en los grupos de base societaria - en los que la dirección unitaria se ejerce a través del derecho de voto de la matriz en la Junta General de las filiales (lo que permitirá impartir instrucciones al órgano de administración o someter a su autorización la adopción por dicho órgano de decisiones o acuerdos sobre determinados asuntos de gestión ex artículo 161 LSC), así como en la facultad de nombrar a la mayoría de miembros del órgano de administración ${ }^{50}$ - y en los grupos de base personal, en los que la identidad de los administradores de las distintas sociedades pone de manifiesto la voluntad de máxima integración empresarial.

48 Fuentes Naharro, Mónica. Grupos de sociedades y protección de acreedores (una perspectiva societaria)... op. cit., pág. 78.

49 Fuentes Naharro, Mónica. Grupos de sociedades y protección de acreedores (una perspectiva societaria)... op. cit., pág. 106.

${ }^{50}$ Bustillo Tejedor, Luis. «Los grupos de sociedades». Cuadernos de derecho y comercio. 2014, n. ${ }^{\circ} 62$, pág. 43. 
Como consecuencia de este singular modo de organizar la empresa, se producen alteraciones tanto en la estructura societaria de las filiales como de la matriz. Así, para este último caso valga como ejemplo el siguiente supuesto: una sociedad adquiere o constituye otra sociedad (convirtiéndose una y otra en matriz y filial, respectivamente) para cederle el uso y explotación de ciertos activos. Consecuentemente, la Junta General de la matriz dejará de controlar y de poder tomar decisiones sobre esos activos, correspondiendo su gestión al órgano de administración de la filial según las instrucciones procedentes de los administradores de la matriz ${ }^{51}$ (a través, entre otras vías, de su voto en la Junta General de la filial como representantes de la matriz). En este sentido, se puede hablar de una pérdida de soberanía de los socios de la matriz en favor de sus administradores ${ }^{52}$. También se distorsiona la estructura societaria de la filial. Esta distorsión se aprecia, en primer lugar, desde un punto de vista meramente organizativo: en este caso, son los dos órganos de gobierno (la Junta General y el órgano de administración) los que quedan limitados por la política económica que, en su caso, decida llevar a cabo el órgano titular de la dirección unitaria. La profesora Fuentes Naharro tilda este fenómeno de «usurpación de competencias orgánicas»" ${ }^{53}$. En segundo lugar, se produce una distorsión desde el punto de vista patrimonial: es habitual que se produzca un mercado interno dentro del grupo, organizado en función de lo que sea más conveniente en términos de estrategia empresarial (un intercambio de bienes, servicios, derechos y obligaciones intragrupo en el marco de las llamadas «operaciones vinculadas») $)^{54}$. Buen ejemplo de ello es el cash-pooling, un habitual mecanismo de préstamos automáticos intragrupo consistente en «un acuerdo entre todas (o varias) sociedades de un mismo grupo que tiene por objeto la gestión de una cuenta corriente bancaria centralizada (pool o master account) por parte de una de ellas (sociedad pooler) en la cual se vierten con carácter periódico — normalmente diario- los saldos de activos y pasivos de las cuentas corrientes bancarias (periféricas) de las diversas sociedades que componen ese grupo ${ }^{55}$ (Fuentes Naharro). La

51 Paz-Ares Rodríguez, Cándido. «Uniones de empresas y grupos de sociedades»... op. cit., pág. 640 .

52 IrÁCUlis ArRegui, Nerea. «Derecho de separación del socio externo de la sociedad matriz y de la filial: controvertida construcción de este mecanismo de protección». Revista de Derecho Mercantil. 2018, n. ${ }^{\circ}$ 308, pág. 37.

${ }_{53}$ Fuentes Naharro, Mónica. Grupos de sociedades y protección de acreedores (una perspectiva societaria)... op. cit., págs. 78 y ss. En el mismo sentido, Paz-Ares Rodríguez, Cándido. «Uniones de empresas y grupos de sociedades»... op. cit., págs. 640 y 641.

${ }^{54}$ Paz-Ares Rodríguez, Cándido. «Uniones de empresas y grupos de sociedades»... op. cit., pág. 641 .

55 Fuentes Naharro, Mónica. «El contrato de «cash pooling»». Revista de derecho mercantil. 2014, n. ${ }^{\circ} 291$, pág. 235. 
función económica es, por tanto, el ahorro de costes financieros gracias a la gestión unitaria de aquella «cuenta centralizada» ${ }^{56}$ (sin perjuicio de que las operaciones financieras intragrupo, como tales operaciones vinculadas hayan de realizarse a condiciones de mercado).

El propio modelo organizativo del grupo acaba produciendo en la práctica situaciones para las que el Derecho común de sociedades no tiene respuesta alguna. A efectos del presente trabajo, se centrará la atención en el daño patrimonial que pueden sufrir las sociedades filiales con causa en una política de grupo ${ }^{57}$. Daño que soportarán directamente los socios de la sociedad perjudicada, e indirectamente sus acreedores ${ }^{58}$.

\subsection{Mecanismos tuitivos de socios externos y acreedores}

Los socios externos, desde un punto de vista formal son aquellos socios de la sociedad dependiente que no tengan participación, directa o indirecta, en el capital de la sociedad dominante ${ }^{59}$. No obstante, un importante sector doctrinal aboga por una definición más amplia, en la que quepan todos los socios que no pertenezcan al círculo de poder del grupo (incluyendo a los de la sociedad dominante) ${ }^{60}$. En cualquier caso, se trata de los socios merecedores de una protección especial porque son los que van a tener que «soportar» el sometimiento ${ }^{61}$ de su sociedad a una política

${ }^{56}$ Fuentes Naharro, Mónica. «El contrato de «cash pooling»»»... op. cit., pág. 237.

57 Precisamente en el daño patrimonial que pueden sufrir las sociedades filiales con causa en una política de grupo es donde radica el debate doctrinal en materia de grupos. Se trata de determinar qué interés es prioritario en tal supuesto: el interés social reconocido y garantizado en la LSC o el interés de grupo (vid. infra apartado III. B).

${ }_{58}$ Fuentes Naharro, Mónica. Grupos de sociedades y protección de acreedores (una perspectiva societaria)... op. cit., pág. 81.

${ }_{59}$ Definición de socios externos del artículo 291-15 ACM.

${ }^{60}$ IRÁCUlis ARregui, Nerea. «Derecho de separación del socio externo de la sociedad matriz y de la filial... op. cit, pág. 2. En el mismo sentido, Fuentes NaHARro, Mónica. Grupos de sociedades y protección de acreedores (una perspectiva societaria)... op . cit., pág. 93. En contra De Arriba Fernández, María Luisa. Derecho de grupos de sociedades... op. cit., págs. 173 y ss., que solo considera como socios externos, como merecedores de protección, a los de las sociedades filiales.

${ }^{61}$ No hay consenso respecto a si la protección especial debe extenderse a los socios de las sociedades integradas en un grupo paritario. Vid. Fuentes Naharro, Mónica. Grupos de sociedades y protección de acreedores (una perspectiva societaria)... op. cit., pág. 91, que considera que las sociedades que forman un grupo por coordinación están igualmente supeditadas a la dirección unitaria y por lo tanto sus socios externos son igualmente merecedores de mecanismos tuitivos (aunque la dirección unitaria sea acordada por todas las sociedades del grupo y no impuesta por una de ellas), por lo que puede redundar igualmente en perjuicios para una de las sociedades integrantes. En el mismo sentido, 
económica común impuesta desde el exterior (lo que en ocasiones redundará en perjuicios patrimoniales para su sociedad y por lo tanto también para el socio en cuestión, ya que su objetivo no es maximizar el rendimiento del grupo, sino de la sociedad en la que han invertido ${ }^{62}$ ). Algunos autores llegan incluso a plantear que el reconocimiento de la legitimidad del interés del grupo (que será lo que permitirá a los administradores de la filial ejecutar instrucciones perjudiciales que redunden en beneficio del grupo) constituye una novación causal del contrato de sociedad ${ }^{63}$ (vid. infra apartado V). Este planteamiento ha dado lugar a cuestionar si la mera integración de una sociedad en un grupo es causa con virtualidad suficiente como para fundamentar el derecho de separación del socio externo ${ }^{64}$. Si bien la integración en un grupo no aparece como causa legal de separación del artículo 346.1 LSC, sí lo hace la sustitución o modificación sustancial del objeto social (artículo 346.1.a) LSC). La cuestión, por tanto, está en determinar si se puede entender que la integración de una sociedad en un grupo constituye una modificación tácita del objeto social. La jurisprudencia parece acoger dicha interpretación, al alejarse de interpretaciones formalistas del precepto y entender que también acoge modificaciones efectivas del objeto social, y no únicamente modificaciones formales ${ }^{65}$. Así se desprende de la STS de 10 de marzo $^{66}$, que determina que el fin de la norma es respetar la voluntad del socio que ingresó en una sociedad que explotaba un determinado negocio, admitiendo por tanto que el mismo condicione su permanencia a la de la finalidad objetiva que fue la base de su relación con aquella. Es decir, que el socio podrá separarse de la sociedad cuando, aun sin haberse producido una efectiva modificación estatutaria, la sociedad se ha convertido en una realidad jurídica o económica distinta $^{67}$ (lo que ocurrirá de forma recurrente en las operaciones de

SACRISTÁn REPRESA, Marcos. «El grupo de estructura paritaria: caracterización y problemas», Revista de Derecho Mercantil. 1982, n. ${ }^{\circ}$ 165-166, págs. 439-440.

62 Paz-Ares Rodríguez, Cándido. «Uniones de empresas y grupos de sociedades»... op. cit., págs. 643 y ss.

${ }^{63}$ Paz-Ares Rodríguez, Cándido. ¿Derecho común o derecho especial de grupos?... op. cit., pág. 29.

${ }^{64}$ El ACM en su artículo 291-16 sí prevé el derecho de separación del socio externo de la sociedad dependiente en el momento de la integración de la misma en un grupo, con derecho a obtener el valor razonable de las acciones o participaciones de que fuere titular.

${ }^{65}$ IrÁCulis ArRegui, Nerea. «Derecho de separación del socio externo de la sociedad matriz y de la filial... op. cit, pág. 10 .

${ }^{66}$ Sentencia del Tribunal Supremo (Sala Primera) n. ${ }^{\circ}$ 102/2011, de 10 de marzo, Ref. Aranzadi, RJ 2011/2765, F. j. 2.

${ }^{67}$ IRÁCUlis ARREGUI, Nerea. «Derecho de separación del socio externo de la sociedad matriz y de la filial... op. cit, pág. 10 . 
filialización, en las que una sociedad operativa se reestructura como holding, segregando sus principales activos a favor de sociedades de nueva creación a cambio de acciones o participaciones de estas) ${ }^{68}$.

También se ha debatido sobre la necesidad de otorgar una protección especial a los acreedores de una sociedad cuyo patrimonio se vea reducido como consecuencia de una política del grupo (ya que el capital de la empresa es una garantía de cobro para el acreedor). Esta tesis no encuentra un amplio consenso en la doctrina. Así, Paz-Ares considera que la problemática con los acreedores no es específica de los grupos de sociedades. En su opinión, los acreedores únicamente pueden acogerse a las normas de defensa del capital de las sociedades (tendentes a evitar su descapitalización), no pudiendo exigir que la sociedad actúe en conformidad con el interés social ${ }^{69}$.

En principio, y como consecuencia de no tener una regulación específica sobre grupos de sociedades, la única protección de socios externos (y acreedores, en su caso) frente a las mencionadas políticas perjudiciales del grupo la brindan los mecanismos ordinarios de impugnación de acuerdos sociales por contravención del interés social (artículo 204.1 LSC) y de exigencia de responsabilidad a los administradores de la filial por no actuar en el mejor interés de la sociedad que administran e infringir por tanto su deber legal de lealtad (artículos 227.1 y 238.1 LSC). El empleo de estas vías ordinarias presenta dos inconvenientes. En primer lugar, la dificultad de probar la inadecuación al interés social. En segundo lugar, no se consigue imputar la responsabilidad al sujeto del que deriva la instrucción perjudicial (el titular de la dirección unitaria) ${ }^{70}$, dando lugar a una ruptura del tradicional binomio poder-responsabilidad ${ }^{71}$. Por eso, se han articulado de lege lata una serie de mecanismos para dar una solución a los mencionados problemas, que fundamentan la exigencia de responsabilidad al titular de la dirección unitaria de una manera razonable: la filial no tiene obligación alguna de soportar las consecuencias perjudiciales de las políticas de grupo, por lo que está autorizada para reclamar el daño sufrido. Naturalmente, esta tesis no es predicable de los grupos contractuales, en los que sí se habrá previsto la obligación de ejecutar instrucciones perjudiciales procedentes del titular

${ }^{68}$ Paz-Ares Rodríguez, Cándido. «Uniones de empresas y grupos de sociedades»... op. cit., pág. 642 .

${ }^{69}$ Paz-Ares Rodríguez, Cándido. «Uniones de empresas y grupos de sociedades»... op. cit., págs. 646 y 647.

${ }^{70}$ El artículo 291-12 ACM, consciente de esta paradoja, hace responsable a la sociedad dominante y a sus administradores del perjuicio causado a la sociedad dependiente por las instrucciones injustas (en el sentido en que se explicará más adelante) impartidas a los administradores de ésta.

71 Fuentes Naharro, Mónica. Grupos de sociedades y protección de acreedores (una perspectiva societaria)... op. cit., pág. 80. 
de la dirección unitaria ${ }^{72}$, ni tampoco de los grupos de base societaria en los que la filial es una sociedad unipersonal (grupos planos), puesto que no habrá socios externos necesitados de especial protección, y porque se identifican las decisiones de la matriz con las decisiones del socio único ${ }^{73}$.

Dichos mecanismos son tres: considerar a la sociedad dominante como administradora de hecho, comunicar responsabilidades mediante el levantamiento del velo societario e imponer un deber de fidelidad especial al socio de control. También se hará breve referencia a otras aportaciones doctrinales que tratan de resolver la problemática.

\subsubsection{Sociedad dominante como administradora de hecho}

El artículo 236.3 LSC extiende la responsabilidad a los administradores de hecho, entendiendo como tales, entre otros supuestos, a las personas bajo cuyas instrucciones actúen los administradores de la sociedad. Esta definición podría extrapolarse a los grupos de sociedades (sobre todo a los jerárqui$\cos$ ), en los que el titular de la dirección unitaria (normalmente la sociedad matriz a través de su órgano de administración $)^{74}$ dicta instrucciones a los administradores de las filiales.

No obstante, la existencia de un grupo de sociedades (aunque sea jerárquico) no es suficiente fundamentar la existencia de un administrador de hecho. Habrá que estudiar el caso concreto para determinar hasta qué punto es la sociedad matriz la encargada de la gestión efectiva de la filial, relevando a los administradores de esta última. Por definición, se debe excluir la extensión de responsabilidad a los administradores de hecho en los grupos descentralizados, en los que los administradores de la filial tienen un mayor margen de autonomía empresarial ${ }^{75}$.

\subsubsection{Levantamiento del velo societario}

El levantamiento del velo societario, aunque no es un instrumento previsto específicamente para grupos, puede servir para imputar la responsabilidad por

72 De ArRiba Fernández, María Luisa. Derecho de grupos de sociedades... op. cit., págs. 222 y ss.

73 Paz-Ares Rodríguez, Cándido. ¿Derecho común o derecho especial de grupos?... op. cit., pág. 91.

${ }^{74}$ Sobre si la legitimación pasiva corresponde a la sociedad dominante o a sus administradores, vid. Fuentes NaHARro, Mónica. Grupos de sociedades y protección de acreedores (una perspectiva societaria) ... op. cit., págs. 283 y 284.

75 Hernando Cebriá. Luis Hernando. «¿Sociedad dominante administradora de hecho? Más allá del velo corporativo». Revista de Derecho Mercantil, 2011, n. ${ }^{\circ}$ 280, pág. 23. 
daños a la sociedad matriz. En efecto, el Tribunal Supremo define la técnica del levantamiento del velo como «un procedimiento para descubrir, y reprimir en su caso, el dolo o abuso cometido con apoyo en la autonomía jurídica de una sociedad, sancionando a quienes la manejan ${ }^{76}$. Sin embargo, es pacífico considerar que la existencia de un grupo no fundamenta, en sí misma, la aplicación del levantamiento del velo societario sino que requiere que concurran requisitos adicionales ${ }^{77}$ : una confusión de personalidades y patrimonios, e inexistencia de independencia entre sociedades, rompiendo el principio de buena fe negocial (STS de 16 de octubre de 2001) ${ }^{78}$.

En cualquier caso y al igual que en el supuesto anterior (la posible responsabilidad como administrador de hecho de la sociedad dominante), no se presenta como una técnica adecuada para imputar, con carácter general, la responsabilidad de los daños producidos por las instrucciones perjudiciales a la sociedad dominante. El propio Tribunal Supremo, en aras a preservar la seguridad jurídica, ha declarado el carácter restrictivo de la aplicación del mecanismo ${ }^{79}$.

\subsubsection{Deber de fidelidad del socio de control}

Otra posible vía para que el titular de la dirección unitaria responda por los daños causados al patrimonio de la filial con ocasión de una instrucción perjudicial es la aplicación al socio de control del deber de fidelidad que la ley prevé únicamente para los administradores - al menos de forma expresa- en el artículo 227.1 LSC. Con fundamento en el deber genérico de buena fe que preside el ordenamiento (artículo 7 del Código Civil, Cciv en lo sucesivo), y específicamente las relaciones contractuales (artículo 1258 Cciv), se pretende evitar que sean únicamente los administradores los obligados por el deber de fidelidad, pudiendo extenderse a quienes desempeñan materialmente la actividad de administración ${ }^{80}$.

${ }^{76}$ Sentencia del Tribunal Supremo (Sala Primera) n. ${ }^{\circ}$ 21/2005, de 28 de enero. Ref. Aranzadi, RJ $2005 \backslash 1829$ (F. j. $2^{\circ}$ ).

77 Vid. Sentencia de la Audiencia Provincial de Madrid (Sección 10 ${ }^{a}$ ) n. ${ }^{\circ}$ 180/2009, de 4 marzo, Ref. Aranzadi, JUR 2009\236681 (F. J. $6^{\circ}$ ). En este sentido se posicionan, asimismo, Girgado Perandones, Pablo. La responsabilidad de la sociedad matriz y de los administradores en una empresa de grupo. Madrid: Ed. Marcial Pons, 2002, págs. 77 y ss. y PaZ-Ares Rodríguez, Cándido. «Uniones de empresas y grupos de sociedades»... op. cit., págs. 646 y 647.

${ }_{78}$ Sentencia del Tribunal Supremo (Sala Primera) n. ${ }^{\circ}$ 930/2001, de 16 octubre. Ref. Aranzadi, RJ $2001 \backslash 8634$ (F. j. $3^{\circ}$ ).

79 Sentencia del Tribunal Supremo (Sala Primera) n. ${ }^{\circ} 874 / 2011$, de 20 diciembre. Ref. Aranzadi, RJ $2012 \backslash 50$ (F. j. $3^{\circ}$ ).

${ }^{80}$ Girgado Perandones, Pablo. La responsabilidad de la sociedad matriz... op. cit., págs. 136 y ss. 
Este mecanismo tiene importantes inconvenientes: en primer lugar, que solo es predicable de los grupos de base societaria, al exigir que el titular de la dirección unitaria sea socio de la filial. En segundo lugar y como ya se ha tenido ocasión de señalar, la sociedad dominante por el hecho de serlo no se convierte en administrador de hecho, por lo que difícilmente puede argumentarse que en todos los grupos de base societaria los socios de control desempeñan materialmente la actividad de administración. Todo ello sin tener en cuenta el sinsentido que supone comparar la junta general con el órgano de administración: por un lado, la junta no es un órgano permanente (no podría llevar a cabo la gestión de la sociedad). Por otro lado, la junta no tiene competencias sobre determinados asuntos que corresponden en exclusiva al órgano de administración, como gestor y representante de la sociedad ${ }^{81}$.

\subsubsection{Otras aportaciones doctrinales}

Ante la evidente insuficiencia de los mecanismos expuestos, ciertos autores han propuesto vías alternativas para imputar la responsabilidad al titular de la dirección unitaria. Así, la profesora Fuentes Naharro considera que es de aplicación la acción individual de responsabilidad contra los administradores de la matriz ${ }^{82}$. El artículo 241 LSC otorga legitimación activa a los terceros (entendiendo por tal a la sociedad filial) por actos de administradores que lesionen directamente los intereses de aquellos ${ }^{83}$. Girgado, por su parte, propone aplicar por analogía - al haber, en su opinión, identidad de razónel régimen de responsabilidad previsto para el socio único en el artículo 16.3, en virtud del cual el socio único (en este caso, sociedad matriz) responderá frente a la sociedad de las ventajas que directa o indirectamente haya obtenido en perjuicio de ésta como consecuencia de los contratos celebrados entre él y la sociedad (contratos intragrupo) ${ }^{84}$. Hay autores, que llegan incluso a comparar la situación del grupo con otras instituciones jurídicas a los efectos de aplicar sus respectivos regímenes de responsabilidad. Buenos ejemplos de ello son la comparación del grupo con la gestión de negocios

${ }^{81}$ Fuentes Naharro, Mónica. Grupos de sociedades y protección de acreedores (una perspectiva societaria)... op. cit., págs. 300 y ss.

${ }^{82}$ Fuentes Naharro, Mónica. Grupos de sociedades y protección de acreedores (una perspectiva societaria)... op. cit., págs. 311 y ss.

${ }_{83}$ El principal inconveniente de este planteamiento es que corresponderá a los administradores de la filial ejercitar la acción, como representantes de la sociedad. Lo más habitual es que esos administradores sean fieles a la sociedad dominante, que es quien les ha nombrado y quien, a su vez, les puede remover del cargo (situación que se dará siempre en los grupos de base societaria).

${ }^{84}$ Girgado Perandones, Pablo. La responsabilidad de la sociedad matriz... op. cit., págs. 118 y ss. 
ajenos sin mandato de los artículos 1888 y ss. Cciv (al gestionar la sociedad matriz determinados negocios de la sociedad filial por voluntad propia y sin oposición de esta última en caso de que el grupo sea descentralizado ${ }^{85}$, con el mandato tácito (al equiparar la sociedad matriz con el mandatario, la sociedad filial con el mandante y la gestión de la sociedad filial con el objeto del mandato en caso de que el grupo sea centralizado $)^{86}$ o con la sociedad de personas (al considerar que las sociedades integrantes en un grupo han formado una suerte de patrimonio común a la orden de una única política unificada para obtener un beneficio) ${ }^{87}$.

Se trata, en todo caso, de aportaciones que no gozan de consenso doctrinal ni jurisprudencial, por lo que no puede decirse que constituyan, de lege lata, una solución al problema de los grupos de sociedades.

\section{Conflicto de intereses: ¿legitimidad del interés del grupo?}

Ya se ha tenido ocasión de adelantar que la legitimidad de los grupos de sociedades es una cuestión que no se pone en duda en la doctrina ni en la jurisprudencia (vid. supra apartado II.A). La problemática del grupo no deriva, por tanto, de reconocer como legítimo al grupo en cuanto a tal o al poder de dirección unitaria que lo gobierna (aspectos que ya han sido superados), sino en determinar si el grupo puede orientar su política hacia la consecución de su propio interés, que será distinto - y contrario, en ocasiones - al de las distintas sociedades que lo integran ${ }^{88}$. Es necesario, en primer lugar, definir tanto el interés social (individual de cada sociedad) como el interés de grupo, para así poder compararlos y afirmar o negar una posible coexistencia entre ambos.

El interés social está previsto legalmente: el artículo 204.1 LSC permite impugnar acuerdos que sean contrarios al interés social, y el artículo 227.1 LSC impone a los administradores la obligación de obrar en el mejor interés de la sociedad (en el marco del más amplio deber de lealtad), y consecuentemente, el deber de «adoptar las medidas necesarias para evitar incurrir en

${ }^{85}$ De Arriba Fernández, María Luisa. Derecho de grupos de sociedades... op. cit., págs. 401 y ss. En contra de este planteamiento, Bustillo TEJEDor, Luis. «Los grupos de sociedades»... op. cit., pág. 45, al considerar que en los grupos de sociedades falta un elemento esencial de la gestión de negocios ajenos sin mandato: la absentia domini, la ausencia del dueño del negocio.

${ }^{86}$ De Arriba FernándeZ, María Luisa. Derecho de grupos de sociedades... op. cit., págs. 411 y ss.

${ }^{87}$ Moya Ballester, Jorge. «Nuevas formas de protección de terceros en el derecho de grupos». Revista de Derecho de Sociedades, 2017, n. ${ }^{\circ}$ 48, pág. 25.

${ }^{88}$ Fuentes Naharro, Mónica. Grupos de sociedades y protección de acreedores (una perspectiva societaria)... op. cit., pág. 134. 
situaciones en las que sus intereses, sean por cuenta propia o ajena, puedan entrar en conflicto con el interés social y con sus deberes para con la sociedad» (artículo 228 e) LSC). Este último precepto ha dado lugar a serios problemas en cuanto a la aprobación de operaciones vinculadas se refiere. En efecto, el artículo 229 LSC concreta las medidas necesarias para evitar incurrir en conflictos de interés, entre las que se encuentra la abstención de realizar transacciones con la sociedad, excepto que se trate de operaciones ordinarias (229.1.a) LSC). Teniendo en cuenta que el apartado segundo del mencionado artículo extiende su aplicación también en el caso de que el beneficiario de los actos o de las actividades prohibidas sea una persona vinculada al administrador, se ha planteado la duda de si el administrador dominical debería abstenerse de la votación en los casos de aprobación de operaciones vinculadas con sociedades del grupo. Tradicionalmente, dicho problema se solucionaba argumentando la inexistencia de conflicto de interés (tesis que se expondrá más adelante), con fundamento en que la norma de la abstención es predicable únicamente de sociedades en situación de dependencia, en las que las operaciones vinculadas son algo esporádico y puntual, y no así de las sociedades integradas en un grupo, en las que a consecuencia de la dirección unitaria, las transacciones intragrupo son recurrentes y estructurales, formando parte de la dinámica de dicha forma de empresa ${ }^{89}$. Actualmente esta aparente contrariedad ha quedado superada por la modificación de la LSC llevada a cabo por la Ley 5/2021, de 12 de abril, por la que se modifica el texto refundido de la Ley de Sociedades de Capita ${ }^{90}$. La modificación incluye como personas vinculadas al administrador a los socios representados por el administrador en el órgano de administración en el artículo 231.1.e) LSC (es decir, a la sociedad matriz), para posteriormente aportar una excepción a la abstención en el nuevo artículo 231 bis relativo a las operaciones intragrupo. Así, su apartado segundo cambia la regla de la abstención por la regla de la inversión de la carga de la prueba: los administradores dominicales podrán votar, pero «si la decisión o voto de tales administradores resultara decisivo para la aprobación, corresponderá a la sociedad y, en su caso, a los administradores afectados por el conflicto de interés, probar que el acuerdo es conforme con el interés social en caso de que sea impugnado» ${ }^{91}$.

89 Paz-Ares RodríGuez, Cándido, «Operaciones vinculadas y grupos de sociedades». En Emparanza Sobejano, Alberto, Martín Osante, José Manuel y Zurimendi Isla, Aitor. Homenaje al profesor José María de Eizaguirre (págs. 291-313). Bilbao: Universidad del País Vasco/Euskal Herriko Unibertsitatea, Servicio Editorial, 2020, pág. 296.

${ }^{90}$ BOE-A-2021-5773.

91 Esta modificación está en la línea de lo que ya propuso el profesor Paz-Ares con anterioridad a la reforma. Vid. PAZ-Ares RodríGuez, Cándido. ¿Derecho común o derecho especial de grupos?... op. cit., págs. 185 y ss. 
El interés de grupo, por su parte, no está reconocido legalmente, pero se deriva implícitamente de la propia existencia de esta forma de organizar la empresa $^{92}$. Es preciso recordar que en apartados precedentes se hacía mención a la dirección unitaria como elemento característico del grupo, planificador de su política económica y de sus líneas de actuación. De la definición de la dirección unitaria se desprende la propia del interés de grupo como el fin o misión de dicha dirección económica unificada ${ }^{93}$, o como «el parámetro que ha de guiar a la sociedad matriz en la dirección del grupo $»^{94}$ (De Arriba Fernández). En el sentido contrario, «el corolario ejecutivo del interés de grupo es el poder de dirección $»^{95}$ (Embid Irujo).

El reconocimiento implícito del interés del grupo queda reducido a su mínima expresión, pues supone que todas las decisiones que adopte el titular de la dirección unitaria deberán respetar siempre y en todo lugar el interés social de cada una de las sociedades integradas, ya que este último sí está previsto legalmente ${ }^{96}$. Ello conduce irremediablemente a una paradoja en el funcionamiento del grupo: por un lado, se reconoce su legitimidad como empresa policorporativa con capacidad de dirigir el grupo, a través de la dirección unitaria hacia un objetivo empresarial común. Por otro lado, se somete a los administradores de la filial a responsabilidad por infracción del deber de lealtad en caso de acatamiento de una instrucción perjudicial procedente del titular de la dirección unitaria, y los acuerdos adoptados con el voto del socio de control en la junta general de la filial pueden ser dejados sin efecto ante una posible impugnación por contravención del interés social (ex. artículo 190.3 LSC) ${ }^{97}$. Todo ello aun cuando el grupo en su conjunto salga fortalecido de la ejecución de dicha instrucción.

Para resolver la mencionada paradoja y hasta que el Derecho positivo pase a regular la materia debidamente, la doctrina ha asumido la complicada tarea de buscar mecanismos que de lege lata permitan legitimar la prioridad del interés de grupo frente al interés social, sin renunciar a este último. Como forma de dar respuesta al conflicto surgió entre la doctrina italiana previa a la reforma del Codice Civile (que regula sistemáticamente los grupos) la teoría

${ }_{92}$ En los ordenamientos que regulan sistemáticamente los grupos de sociedades, tal legitimación es explícita.

93 IRÁCUlis ARREGUI, Nerea. «Interés del grupo y daño patrimonial por acatamiento de una instrucción ilegítima... op. cit., pág. 7.

${ }^{94}$ De Arriba Fernández, María Luisa. Derecho de grupos de sociedades... op. cit., 215.

95 Embid Irujo, José Miguel. «El derecho de los grupos de sociedades: entre las medidas de tutela y la organización de la empresa policorporativa»... (versión electrónica).

${ }^{96}$ Fuentes Naharro, Mónica. Grupos de sociedades y protección de acreedores (una perspectiva societaria)... op. cit., pág. 146.

97 Fuentes Naharro, Mónica. «Conflictos de interés en grupos de sociedades: a propósito de la STS 12 de abril de 2007 (RJ 2007, 2410)». Revista de Derecho de Sociedades, 2008, n. ${ }^{\circ} 30$, pág. 414. 
de las ventajas compensatorias, avalada por la Cour de Cassation francesa en 1985 en el famoso caso Rozenblum ${ }^{98}$.

\section{LEGITIMIDAD DEL INTERÉS DE GRUPO EN LA JURISPRUDENCIA ESPAÑOLA A TRAVÉS DE LA TEORÍA DE LAS VENTAJAS COMPENSATORIAS}

\section{Antecedentes, aplicación jurisprudencial de la teoría de y acogida a nivel comunitario}

El profesor Paz-Ares, aun cuando no comparte la teoría de las ventajas compensatorias (vid. infra apartado $\mathrm{V}$ ), ofrece una buena definición de la misma: «Una decisión prima facie contraria al interés social de la filial puede ser adoptada en atención al interés del grupo cuando el sacrificio que supone para la filial es proporcionado o resulta compensado», entendiendo que es proporcionado cuando «forma parte de una estrategia general del grupo que ofrece a largo plazo un equilibrio interno entre ventajas e inconvenientes» (compensación genérica), y que resulta compensado cuando «el grupo haya arbitrado o arbitre con posterioridad medidas dirigidas específicamente a compensar a la filial o a sus accionistas minoritarios» (compensación específica $)^{99}$. Mientras que el Derecho alemán opta por esta última opción (artículos 311 y ss. Aktiengesetz), el caso Rozenblum al que se hacía referencia aboga por una compensación genérica, al igual que el Codice Civile italiano en su artículo 2497 y que el ACM en su artículo 291-10. Se trata, en definitiva, de que las ventajas que proporciona a la filial la pertenencia a un grupo equilibren los daños que puede provocarle el acatamiento de las instrucciones perjudiciales emitidas por el titular de la dirección unitaria ${ }^{100}$, ya que, en palabras de la STS de 12 de abril de 2007, «la integración de una sociedad en un grupo puede ser beneficiosa para la misma, en el sentido de favorecer su actuación concurrencial la agrupación de esfuerzos, la organización de medios y la planificación de objetivos comunes o coordinados que, como regla, aquel genera». En caso de que la pertenencia a un grupo no sea suficiente para equilibrar ese «balance general», la sociedad filial deberá recibir una compensación adecuada ${ }^{101}$.

${ }^{98}$ En este mismo sentido, el también paradigmático caso Tetrafin, de la Corte de Apelación de Milán de 11 de julio 1991.

99 Paz-Ares Rodríguez, Cándido. ¿Derecho común o derecho especial de grupos?... op. cit., pág. 240 .

100 Paz-Ares Rodríguez, Cándido. ¿Derecho común o derecho especial de grupos? ... op. cit., pág. 241.

101 Puede parecer, prima facie, que la teoría de las ventajas compensatorias es contraria al artículo 1686 Cciv, que prohíbe la compensatio lucri al disponer que «Todo socio 
La teoría de las ventajas compensatorias fue expresamente avalada por el Alto Tribunal en su sentencia de 11 de diciembre de $2015^{102}$. En este sentido, confirma la necesidad de encontrar un equilibrio razonable entre el interés del grupo y el interés particular de cada una de las sociedades que lo integran, con el objetivo de hacer posible «el funcionamiento eficiente y flexible de la unidad empresarial que supone el grupo de sociedades», pero evitando, al mismo tiempo, «el expolio de las sociedades filiales y la postergación innecesaria de su interés social». La solución que propone el Tribunal Supremo es buscar ese equilibrio «en la existencia de ventajas compensatorias que justifiquen que alguna actuación, aisladamente considerada, pueda suponer un perjuicio para la sociedad», decantándose por una modalidad de compensación genérica, al exigir la realización de un balance «de las ventajas facilitadas o las prestaciones realizadas en ambas direcciones (de la sociedad al grupo y del grupo a la sociedad) y concluir si existe o no un resultado negativo para la sociedad filial». Esto implica que las ventajas recibidas en contraprestación no tienen porqué ser simultáneas o posteriores al daño sufrido. La idea de un balance general permite también puedan ser anteriores, con lo que en el momento de la causación del daño, este ya estará compensado. En cualquier caso, la sentencia establece una serie de requerimientos para que las ventajas puedan entenderse como compensatorias del daño causado. Así, deben ser: (i) verificables «sin que sean suficientes meras hipótesis, invocaciones retóricas a «sinergias» o a otras ventajas faltas de la necesaria concreción» (aunque sí cabe que consistan en oportunidades concretas de negocio); (ii) valorables económicamente; (iii) proporcionales al daño sufrido por la sociedad filial; (iv) justificadas ${ }^{103}$; y (v) respetuosas, en todo caso, con la pervivencia de la sociedad filial ${ }^{104}$. Se echa en falta la referencia a un límite temporal en el cual el daño deba verse compensado. En el Derecho

debe responder a la sociedad de los daños y perjuicios que ésta haya sufrido por culpa del mismo y no puede compensarlos con los beneficios que por su industria le haya proporcionado». La profesora Fuentes Naharro ofrece una acertada solución, al interpretar que la ventaja que recibe la filial no tiene la finalidad de reparar o indemnizar un daño, sino de reequilibrar sino de o actuar de contraprestación a la desventaja sufrida en aras al interés de grupo. Vid. Fuentes Naharro, Mónica. Grupos de sociedades y protección de acreedores (una perspectiva societaria)... op. cit., págs. 155 y ss.

${ }^{102}$ La más antigua STS de 12 de abril de 2007 regula superficialmente el asunto, sin interpretar los mecanismos necesarios para articular el interés de grupo y el interés social (lo que sí hace la STS de 11 de diciembre de 2015).

${ }^{103}$ En línea con lo exigido por el artículo 291-11.2 ACM, al exigir que se incluyan en el informe de gestión de la sociedad dependiente la causa y, en su caso, la cuantía real o estimada del perjuicio ocasionado a la sociedad por la ejecución de las instrucciones de los administradores de la sociedad dominante y las condiciones de la compensación.

${ }^{104}$ No faltan en la doctrina posturas contrarias a esta exigencia, considerando que si se cumplen el resto de requisitos, la subsistencia de la sociedad no debe actuar como límite en la consecución del interés de grupo. En este sentido, vid. Iráculis Arregui, Nerea. 
proyectado (artículo 291-11.2 ACM) el plazo es de un año (que se contará desde la fecha de la instrucción si el perjuicio fuera objetivamente previsible), transcurrido el cual se entenderá producido el perjuicio al interés social si no se ha producido una compensación adecuada. Sobra decir que, en ese caso, serán de aplicación los mecanismos tuitivos que el Derecho general de sociedades pone a disposición de los socios externos y acreedores.

Esta doctrina también es aplicable para justificar un trato desigual en lo que al pago de intereses generados por el pool se refiere (vid. apartado III.A.1). En efecto, una sociedad puede recibir un trato desfavorable en comparación con otras integradas en ese sistema de gestión de la tesorería si ello se justifica atendiendo al balance global de las ventajas que recibe por la pertenencia al grupo ${ }^{105}$.

La teoría de las ventajas compensatorias ha tenido una amplia acogida, no solo en España, Italia o Francia, sino también a nivel comunitario. Prueba de ello es que el Forum Europaeum, en una de sus propuestas, sugiere considerar que los administradores que forman parte de un grupo no actúan en contra de sus obligaciones siempre que acepten razonablemente la posibilidad de compensar los perjuicios con otro tipo de ventajas en un plazo de tiempo ${ }^{106}$. El Informe Winter y el más reciente EMCA, en líneas generales, hacen el mismo planteamiento. Es de destacar que el ICLEG de 2016 llega incluso a considerar que la doctrina del caso Rozenblum (o asimiladas, según los estados miembros) constituye una suerte de ius commune entre los Estados que reconocen el interés de grupo ${ }^{107}$. Este último informe de expertos, el ICLEG, incluye a España como uno de esos países que reconocen el interés del grupo, y lo hace precisamente a raíz de la STS de 11 de diciembre de 2015. En efecto, acoger la doctrina de las ventajas compensatorias tiene una serie de implicaciones concatenadas que es preciso comentar: acatar una instrucción perjudicial procedente de la matriz, siempre que redunde en beneficio para el grupo, únicamente supone postergar el interés social a la espera de que el daño quede debidamente compensado o neutralizado. Es decir, la sociedad filial desplaza temporalmente el interés social en favor del interés de grupo, pero sin renunciar a su consecución final ${ }^{108}$, puesto que en palabras de la STS de 11 de diciembre de 2015 «la sociedad filial no solo conserva su propia personalidad jurídica, sino también sus concretos objetivos y su propio y específico interés

«Interés del grupo y daño patrimonial por acatamiento de una instrucción ilegítima... op. cit., pág. 26.

105 Fuentes Naharro, Mónica. «El contrato de «cash pooling»»»... op. cit., pág. 251.

106 Forum Europaeum. «Derecho de grupos: por un derecho de los grupos de sociedades». Revista de Derecho Mercantil, 1999, n. ${ }^{\circ}$ 232, págs. 494-495.

${ }^{107}$ Informal Company Law Expert Group (2016). Report on the recognition of the interest of the group, pág. 25 .

108 IRÁCULIS ARREGUI, Nerea. «Interés del grupo y daño patrimonial por acatamiento de una instrucción ilegítima... op. cit., pág. 26. 
social, matizado por el interés del grupo, y coordinado con el mismo, pero no diluido en él hasta el punto de desaparecer». De esta forma, se consigue coordinar los intereses en juego, resolviendo el aparente conflicto al que se hacía alusión con anterioridad, y consecuentemente, se blinda cualquier eventual impugnación del acuerdo por contravenir el interés social, de la misma manera que los administradores de la filial quedan a salvo de la posible exigencia de responsabilidad por no actuar en el mejor interés de la sociedad que administran (todo ello, naturalmente, si el daño queda debidamente compensado en un plazo de tiempo determinado). En definitiva, acoger la doctrina de las ventajas compensatorias supone reconocer la legitimidad del interés de grupo en su máxima expresión: la obligación de compensar solo puede explicarse desde el reconocimiento de un interés distinto del de la sociedad filial, pero igualmente merecedor de protección ${ }^{109}$. El interés de grupo así reconocido actúa, desde una vertiente positiva como legitimador de la dirección unitaria (en el sentido de que están legitimadas las instrucciones perjudiciales procedentes su titular); y desde una vertiente negativa, en el sentido de que la dirección unitaria encuentra como límite el propio interés del grupo (las instrucciones perjudiciales que sirvan a intereses distintos, como el de la sociedad dominante en un grupo jerárquico, serán consideradas ilegítimas) ${ }^{110}$.

\section{Deberes de los administradores}

Ya se ha tenido ocasión de aclarar que, según la teoría de las ventajas compensatorias, resulta improcedente la exigencia de responsabilidad al administrador de la filial por incumplir su deber de actuar en el mejor interés de la sociedad que administra. No obstante, es evidente que la integración de una sociedad en un grupo no puede hacer desaparecer los deberes y responsabilidades de los administradores en cuanto a tales. En efecto, los deberes de lealtad y diligencia subsisten (el artículo 236.2 LSC declara expresamente que la circunstancia de que el acto o acuerdo lesivo haya sido adoptado, autorizado o ratificado por la junta general no exonera de responsabilidad al administrador) $)^{111}$, si bien deben ser matizados e interpretados a la luz de la teoría de las ventajas compensatorias.

109 Bustillo Tejedor, Luis. «Los grupos de sociedades»... op. cit., pág. 45. En el mismo sentido, IRÁCUlis ARREGUI, Nerea. «Derecho de separación del socio externo de la sociedad matriz y de la filial... op. cit, pág. 25.

110 IRÁCUlis ARREGUI, Nerea., «Interés del grupo y daño patrimonial por acatamiento de una instrucción ilegítima... op. cit., pág. 10 y Fuentes NaHARro, Mónica. Grupos de sociedades y protección de acreedores (una perspectiva societaria)... op. cit., págs. 188 y 189.

111 Este precepto viene a significar que la función de gatekeepers de los administradores respecto de la adecuada gestión de la sociedad no decae por el hecho de que los mis- 
El deber de diligencia viene enunciado en el artículo 225 LSC, y se concreta en las siguientes obligaciones: deber de desempeñar el cargo y cumplir los deberes impuestos por las leyes y los estatutos con la diligencia de un ordenado empresario, teniendo en cuenta la naturaleza del cargo y las funciones atribuidas a cada uno de ellos; subordinar, en todo caso, su interés particular al interés de la empresa (225.1 LSC); tener la dedicación adecuada; adoptar las medidas precisas para la buena dirección y el control de la sociedad (225.2 LSC); y exigir y recabar de la sociedad la información adecuada y necesaria que le sirva para el correcto desempeño de sus funciones (225.3 LSC). Así, el deber de diligencia del administrador que recibe una instrucción perjudicial del titular de la dirección unitaria consistirá en asegurarse (recabando de la matriz la información necesaria) de que la operación desventajosa será adecuadamente compensada en un plazo de tiempo determinado. En otras palabras, el administrador debe actuar a modo de filtro, juzgando la legitimidad de la instrucción perjudicial recibida y debiendo rechazar aquellas que no cumplan con los requerimientos para que las ventajas puedan entenderse como compensatorias del daño causado antes enunciados. Consecuentemente, aunque ex post se derive un daño patrimonial para la sociedad filial (porque no son suficientes las ventajas derivadas de la pertenencia al grupo y porque no ha se ha efectuado una compensación adecuada), no se podrá reclamar responsabilidad al administrador si ex ante era razonablemente previsible considerar que la compensación era adecuada y posible $^{112}$ (ya que el administrador habrá actuado diligentemente y por lo tanto no se produce la necesaria imputación subjetiva requerida por el artículo 236.1 LSC $)^{113}$.

En lo que al deber de lealtad se refiere, es necesario interpretar la exigencia del artículo 227.1 LSC en el marco de la coordinación del interés social con el del grupo, resultando este último como una suerte de interés extrasocial $^{114}$. Como ya se ha señalado con anterioridad, el interés de grupo actúa como límite de la dirección unitaria, de manera que solo están legitimadas las instrucciones perjudiciales que redunden en interés del grupo como conjunto. Precisamente por ello, según esta teoría, el administrador de la filial

mos actúen siguiendo instrucciones (aunque el artículo 236.2 se refiere expresamente a instrucciones de la Junta General, se podría aplicar por analogía —al concurrir identidad de razón - a las instrucciones dimanantes del titular de la dirección unitaria para su aplicación a los grupos que no sean de base societaria).

112 Así lo exige el artículo 291-11.2 ACM.

113 IrÁCUlis ArREgUI, Nerea. «Interés del grupo y daño patrimonial por acatamiento de una instrucción ilegítima... op. cit., pág. 29 y Fuentes NaHARro, Mónica. Grupos de sociedades y protección de acreedores (una perspectiva societaria)... op. cit., 209 y ss.

114 Fuentes Naharro, Mónica. Grupos de sociedades y protección de acreedores (una perspectiva societaria)... op. cit., págs. 208 y ss. 
infringirá su deber de lealtad cuando el sujeto beneficiado por la instrucción perjudicial sea la sociedad dominante o un tercero ${ }^{115}$ (ya que en este caso subsiste íntegramente el conflicto de interés que se planteaba en el apartado III.B).

No se puede dar por concluido este apartado sin apuntar que la protección de la discrecionalidad empresarial de que goza un administrador de una sociedad integrada en un grupo se ve seriamente afectada (aunque no ha habido, por el momento, pronunciamientos en este sentido), por la Ley 5/2021, de 12 de abril. En efecto, el artículo 226.2 LSC establece que «no se entenderán incluidas dentro del ámbito de discrecionalidad empresarial aquellas decisiones que afecten personalmente a otros administradores y personas vinculadas (...)», mientras que la Ley 5/2021 modifica el artículo 231.1 LSC e incluye como persona vinculada al administrador «los socios representados por el administrador en el órgano de administración». Esto puede suponer un desincentivo para los administradores a la hora de asumir riesgos en la gestión de la sociedad, ya que no estarán protegidos por el estándar de conducta que supone la regla del artículo 226.2 LSC (también conocida como Business Judgement Rule por su origen en el Derecho anglosajón) ${ }^{116}$.

\section{CRÍTICA A LA TEORÍA DE LAS VENTAJAS COMPENSATORIAS}

Pese a la general acogida de la teoría de las ventajas compensatorias, no han faltado entre la doctrina voces discordantes, que basan su crítica en la ausencia de legitimidad del interés de grupo en el ordenamiento jurídico (ya sea explícita o implícitamente) ${ }^{117}$. Además, en opinión de Paz-Ares, la doctrina mencionada yerra en su planteamiento más básico, puesto que considera inviable coordinar dos intereses que, por definición, están contrapuestos. En otras palabras, la maximización conjunta del interés del grupo y del de las filiales no es posible, y ello porque «cuando una parte de la transacción tiene influencia sobre la contraparte, el riesgo de que la utilice

115 IrÁCULIS ARREgUi, Nerea. «Interés del grupo y daño patrimonial por acatamiento de una instrucción ilegítima... op. cit., pág. 27.

116 García De Enterría, Javier, e Iglesias Prada, Juan. «Los órganos de las sociedades de capital (II). Los administradores». En: Menéndez Menéndez, Aurelio y Rojo, Ángel (dirs.). Lecciones de Derecho Mercantil (págs. 505-526). Cizur Menor: Ed. Civitas, 2019, pág. 521.

${ }_{117}$ El profesor Paz-Ares considera que de la legitimidad del grupo no se desprende, en ningún caso, la legitimidad del interés de grupo. Antes al contrario, considera que si el legislador es consciente de la existencia de los grupos pero no entra a regularlos, es porque su voluntad es primar el interés social en cualquier circunstancia. Vid. PAZ-Ares RodríGUEZ, Cándido. ¿Derecho común o derecho especial de grupos?... op. cit., pág. 37. 
para avanzar el interés propio, en lugar de para promover el ajeno (como debería), es inevitable» ${ }^{118}$.

Otra crítica bien fundada a la teoría de las ventajas compensatorias en los países que no regulan sistemáticamente los grupos de sociedades es que no da una respuesta a la novación causal del contrato de sociedad que se produce al conceder carta de naturaleza al interés de grupo (vid. supra apartado III.A.2). En efecto, si se entiende la causa del contrato de sociedad como el fin común que persiguen los socios ${ }^{119}$ (artículo $1666 \mathrm{Cciv}$ ), reconocer el interés de grupo como interés extrasocial que debe guiar la actuación de la sociedad (en virtud de la dirección unitaria) tiene como consecuencia inevitable una novación causal. Es decir, por medio de la constitución de una sociedad, los socios pretenden alcanzar un fin común a todos ellos que deberá ser el criterio orientador de la actuación de los órganos sociales ${ }^{120}$. Dicho fin se verá sustituido por la política económica común en el momento de la integración de la sociedad en un grupo. El ACM parece darse cuenta de ello, y en su artículo 291-16 prevé el derecho de separación del socio externo de la sociedad dependiente con derecho a obtener el valor razonable de las acciones o participaciones de que fuere titular por el mero hecho de que la sociedad se integre en un grupo.

Finalmente, pese a la tendencia favorable a las ventajas compensatorias a nivel comunitario, el ECLE pone en cuestión esta forma de dar solución al conflicto del grupo, por ser poco protectora de los intereses de socios externos y acreedores: «the application of the Rozenblum criteria (...) leaves too wide a discretion to the parent and to the subsidiary concerned, as no limits - quantitative or other - are implied as to the amount of negative influence on the subsidiary, while no time limit is set for the compensating action. The protection for minority shareholders is rather weak $(\ldots)\rangle^{121}$.

\section{CONCLUSIONES}

Del análisis jurídico de la problemática que generan los grupos desde un punto de vista del Derecho de sociedades se derivan las siguientes conclusiones:

118 Paz-Ares Rodríguez, Cándido. «Operaciones vinculadas y grupos de sociedades»... op. cit., pág. 292.

119 PAz-Ares Rodríguez, Cándido. «Las sociedades mercantiles». En: Menéndez Menéndez, Aurelio y Rojo, Ángel (dirs.). Lecciones de Derecho Mercantil (págs. 373389). Cizur Menor: Ed. Civitas, 2019, pág. 373.

120 Paz-Ares Rodríguez, Cándido. ¿Derecho común o derecho especial de grupos?... op. cit., págs. 108 y 109.

${ }^{121}$ ECLE (European company law experts), a proposal for reforming group law in the EU, pág. 33. 
1. En España los grupos de sociedades carecen de una regulación sistemática en el ordenamiento jurídico, más allá de normas sectoriales. Esta ausencia de regulación da lugar a varios problemas. El primero de ellos lo constituyen las contradicciones que se producen sobre el concepto de grupo de sociedades según se trate de una rama u otra del Derecho. En segundo lugar, el desfase existente en el seno del Derecho de sociedades - cuyas disposiciones normativas están previstas para sociedades individualmente consideradas - y la realidad, en la que es frecuente que las sociedades operen conjuntamente en el tráfico económico a través de la formación de grupos. El tercer problema derivado de la ausencia de regulación sobre esta materia es el silencio del legislador sobre la legitimidad del interés de grupo y sobre los mecanismos tuitivos específicos — más allá de lo previsto por la LSC para las sociedades independientes - de que se pueden valer los socios externos de una sociedad integrada en un grupo.

2. La legitimidad de los grupos de sociedades no se pone en duda, por la referencia a los mismos - aunque sea parcial y asistemática - en distintas normas del ordenamiento jurídico y por el reconocimiento de la libertad de empresa en la Constitución. Precisamente de la legitimidad de esta forma de organización empresarial se deriva la legitimidad implícita del interés de grupo, ya que es evidente que el grupo actúa en su mejor interés y el titular de la dirección unitaria toma las decisiones desde una perspectiva global, del conjunto y no de cada una de las sociedades integrantes. No obstante, el reconocimiento implícito del interés de grupo es insuficiente para legitimar una eventual instrucción perjudicial para el patrimonio de la filial procedente del titular de la dirección unitaria, pues queda sometido, en todo caso, al interés social - reconocido legalmente- de cada una de las sociedades que lo integran en caso de conflicto. Ello da lugar a una paradoja: el grupo actúa en su mejor interés pero debe observar como límite el interés social de las sociedades integradas.

3. Para dar respuesta al problema y poder legitimar las eventuales instrucciones perjudiciales para el patrimonio de las filiales procedentes del titular de la dirección unitaria, se ha interpretado de lege lata que en los grupos no se produce conflicto alguno entre el interés grupal y el social si se coordinan debidamente. Tal coordinación se produce cuando el daño sufrido por la filial en acatamiento de una instrucción perjudicial se ve debidamente compensado (ya sea por su pertenencia al grupo o en virtud de una compensación $a d h o c$ ).

4. Es conveniente que se proceda a regular un Derecho de grupos de sociedades. En efecto, aunque la teoría de las ventajas compensatorias ofrece una respuesta razonable al conflicto de grupo, no deja de 
ser una construcción jurisprudencial y en ningún caso se puede decir que constituya la solución. En primer lugar, porque el desarrollo interpretativo del Derecho suele dar lugar a un sinfín de discusiones doctrinales, generando polémica sobre el asunto (como se ha tratado de plasmar en el apartado «crítica a la teoría de las ventajas compensatorias»). En segundo lugar, porque los Tribunales ofrecen una respuesta a posteriori al problema: una vez impugnado el acuerdo o ejercitada la acción de responsabilidad contra los administradores por contravención del interés social. Todo ello conduce a una situación de máxima inseguridad jurídica para los agentes implicados: socios, administradores, sociedades filiales, el grupo en su conjunto, etc. De existir un Derecho positivo sobre la cuestión, el problema quedaría solucionado a priori, antes de que surja el conflicto.

5. Una línea de investigación futura podría ser el estudio de las posibles formas de regular los grupos de sociedades en el ordenamiento jurídico: si sería más conveniente tender hacia un modelo contractual como en Alemania, si por el contrario conviene más acercarse al modelo orgánico italiano, ventajas y desventajas de ambos modelos, etc. ( $\mathrm{ACM})$.

\section{REFERENCIAS}

\section{Bibliografia}

Bustillo Tejedor, Luis. «Los grupos de sociedades». Cuadernos de derecho y comercio. 2014, n. ${ }^{\circ} 62$.

Castro De Luna, Manuel José. «Hacia un modelo contractual del concepto de grupo de sociedades». Revista Quincena Fiscal. 2015, n. ${ }^{\circ} 20$.

De Arriba Fernández, María Luisa. Derecho de grupos de sociedades. Madrid: Ed. Civitas, 2004.

Embid IRujo, José Miguel. «A la búsqueda de un Derecho de grupos en Europa». Gaceta jurídica de la Unión Europea y de la competencia. 2004, n. ${ }^{\circ} 231$.

- «Pautas para el tratamiento de los grupos de sociedades en el marco de la Unión Europea». Noticias de la Unión Europea. 2006, n. ${ }^{\circ} 252$.

«La regulación de los grupos en la Propuesta de Código de Sociedades Mercantiles». En: Estudios de Derecho de sociedades y Derecho concursal. Libro Homenaje al profesor Rafael Garcia Villaverde, I (págs. 389-408). Madrid: Ed. Marcial Pons, 2007.

— «El significado jurídico de los grupos de sociedades. La corporate governance». Ekonomiaz. 2008, n. ${ }^{\circ} 68$.

- «Ante la regulación de los grupos de sociedades en España». Revista de Derecho Mercantil. 2012, n. ${ }^{\circ} 284$. 
«Interés del grupo y ventajas compensatorias. Comentario de la sentencia del Tribunal Supremo (sala primera) de 11 de diciembre de 2015», Revista de Derecho Mercantil. 2016.

— La aportación judicial a la construcción del derecho de los grupos de sociedades. Revista Lex Mercatoria. 2016, n. ${ }^{\circ} 3$.

«El derecho de los grupos de sociedades: entre las medidas de tutela y la organización de la empresa policorporativa». Revista de Derecho Mercantil, 2017, n. ${ }^{\circ} 304$.

FERNÁNDEZ MARKAIDA, Idoia. «Los grupos de sociedades en el derecho comparado: los dos grandes sistemas». En: Los grupos de sociedades como forma de organización empresarial. Madrid: Ed. Edersa, 2006.

Forum Europaeum. «Derecho de grupos: por un derecho de los grupos de sociedades». Revista de Derecho Mercantil, 1999, n. ${ }^{\circ} 232$.

Fuentes Naharro, Mónica. Grupos de sociedades y protección de acreedores (una perspectiva societaria). Cizur Menor: Ed. Aranzadi, 2007.

— «Conflictos de interés en grupos de sociedades: a propósito de la STS 12 de abril de 2007 (RJ 2007, 2410)». Revista de Derecho de Sociedades, 2008, n. ${ }^{\circ} 30$.

- «El contrato de «cash pooling»». Revista de derecho mercantil. 2014, n. ${ }^{\circ} 291$.

García De Enterría, Javier, e Iglesias Prada, Juan. «Los órganos de las sociedades de capital (II). Los administradores». En: Menéndez Menéndez, Aurelio y Rojo, Ángel (dirs.). Lecciones de Derecho Mercantil (págs. 505-526). Cizur Menor: Ed. Civitas, 2019.

Girgado Perandones, Pablo. La responsabilidad de la sociedad matriz y de los administradores en una empresa de grupo. Madrid: Ed. Marcial Pons, 2002.

Hernando Cebriá. Luis Hernando. «¿Sociedad dominante administradora de hecho? Más allá del velo corporativo». Revista de Derecho Mercantil, 2011, n. ${ }^{\circ} 280$.

Iráculis Arregui, Nerea. «Interés del grupo y daño patrimonial por acatamiento de una instrucción ilegítima: responsabilidad por negligencia de los administradores de la sociedad dominada». Revista de Derecho de Sociedades, 2017, n. ${ }^{\circ} 49$.

— «Derecho de separación del socio externo de la sociedad matriz y de la filial: controvertida construcción de este mecanismo de protección». Revista de Derecho Mercantil. 2018, n. 308.

Moya BALlester, Jorge. «Nuevas formas de protección de terceros en el derecho de grupos». Revista de Derecho de Sociedades, 2017, n. ${ }^{\circ} 48$.

Paz-Ares Rodríguez, Cándido. ¿Derecho común o derecho especial de grupos? Esa es la cuestión. Pamplona: Ed. Civitas, 2019.

—Las sociedades mercantiles». En: Menéndez Menéndez, Aurelio y Rojo, Ángel (dirs.). Lecciones de Derecho Mercantil (págs. 373-389). Cizur Menor: Ed. Civitas, 2019.

— «Uniones de empresas y grupos de sociedades». En: Menéndez Menéndez, Aurelio y Rojo, Ángel (dirs.). Lecciones de Derecho Mercantil (págs. 631-648). Cizur Menor: Ed. Civitas, 2019.

- «Operaciones vinculadas y grupos de sociedades». En: EMPARANZA SobEJAno, Alberto, Martín Osante, José Manuel y Zurimendi Isla, Aitor. Homenaje 
al profesor José María de Eizaguirre (págs. 291-313). Bilbao: Universidad del País Vasco/Euskal Herriko Unibertsitatea, Servicio Editorial, 2020.

SACRISTÁN REPRESA, Marcos. «El grupo de estructura paritaria: caracterización y problemas», Revista de Derecho Mercantil. 1982, n. ${ }^{\circ}$ 165-166.

\section{Legislación}

España. Constitución Española. «BOE» n. ${ }^{\circ} 311$, de 29 de diciembre de 1978, páginas 29313 a 29424.

- Ley 37/1992, de 28 de diciembre, del Impuesto sobre el Valor Añadido. «BOE» n. ${ }^{\circ} 312$, de 29 de diciembre de 1992, páginas 44247 a 44305.

— Ley 27/1999, de 16 de julio, de Cooperativas. «BOE» n. ${ }^{\circ} 170$, de 17 de julio de 1999, páginas 27027 a 27062.

— Ley 15/2007, de 3 de julio, de Defensa de la Competencia. «BOE» n. ${ }^{\circ}$ 159, de 4 de julio de 2007, páginas 28848 a 28872.

— Ley 16/2007, de 4 de julio, de reforma y adaptación de la legislación mercantil en materia contable para su armonización internacional con base en la normativa de la Unión Europea. «BOE» n. ${ }^{\circ}$ 160, de 5 de julio de 2007, páginas 29016 a 29047.

— Ley 27/2014, de 27 de noviembre, del Impuesto sobre Sociedades. «BOE» n. ${ }^{\circ} 288$, de 28 de noviembre de 2014, páginas 96939 a 97097.

_ Ley 5/2021, de 12 de abril, por la que se modifica el texto refundido de la Ley de Sociedades de Capital, aprobado por el Real Decreto Legislativo 1/2010, de 2 de julio, y otras normas financieras, en lo que respecta al fomento de la implicación a largo plazo de los accionistas en las sociedades cotizadas. «BOE»n. ${ }^{\circ} 88$, de 13 de abril de 2021, páginas 40928 a 40980.

— Real Decreto Legislativo 1/2010, de 2 de julio, por el que se aprueba el texto refundido de la Ley de Sociedades de Capital. «BOE» n. ${ }^{\circ} 161$, de 3 de julio de 2010, páginas 58472 a 58594.

— Real Decreto Legislativo 4/2015, de 23 de octubre, por el que se aprueba el texto refundido de la Ley del Mercado de Valores. «BOE» n. ${ }^{\circ} 255$, de 24 de octubre de 2015, páginas 100356 a 100541.

— Real Decreto de 22 de agosto de 1885 por el que se publica el Código de Comercio. «Gaceta de Madrid» n. ${ }^{\circ}$ 289, de 16 de octubre de 1885, páginas 169 a 170.

\section{Jurisprudencia}

Sentencia del Tribunal Supremo (Sala Primera) n. ${ }^{o}$ 930/2001, de 16 octubre de 2001. Ref. Aranzadi, RJ 2001 $\backslash 8634$ (F. j. $3^{\circ}$ ).

— (Sala Primera) n. ${ }^{\circ} 21 / 2005$, de 28 de enero de 2005. Ref. Aranzadi, RJ $2005 \backslash 1829$.

(Sala Cuarta) de 3 de noviembre de 2005, rec. 3400/2004. Ref. Aranzadi, RJ $2006 \backslash 1244$.

— (Sala Primera) n. ${ }^{\circ}$ 400/2007, de 12 de abril de 2007. Ref. Aranzadi, RJ $2007 \backslash 2410$. 
(Sala Primera) n. ${ }^{\circ}$ 102/2011, de 10 de marzo de 2011. Ref. Aranzadi, RJ $2011 / 2765$.

(Sala Primera) n. ${ }^{\circ} 874 / 2011$, de 20 de diciembre de 2011. Ref. Aranzadi, RJ $2012 \backslash 50$.

(Sala Cuarta) de 23 de octubre de 2012, rec. 351/2012. Ref. Aranzadi, RJ $2012 \backslash 10711$.

- (Sala Cuarta) de 27 de mayo de 2013, rec. 78/2012. Ref. Aranzadi, RJ $2013 \backslash 7656$.

(Sala Cuarta) de 20 de octubre de 2015, rec. 172/2014. Ref. Aranzadi, RJ $2015 \backslash 5210$.

(Sala Primera) n. ${ }^{\circ}$ 695/2015, de 11 de diciembre de 2015. Ref. Aranzadi, RJ $2015 \backslash 5440$.

Sentencia de la Audiencia Provincial de Vizcaya (Sección $3^{a}$ ) n. ${ }^{\circ}$ 311/2002, de 13 de junio de 2002. Ref. Aranzadi, JUR 2002\211271.

Sentencia de la Audiencia Provincial de Madrid (Sección 10a) n. ${ }^{\mathrm{o}} 180 / 2009$, de 4 marzo de 2009. Ref. Aranzadi, JUR 2009\236681. 


\title{
ANÁLISIS DE LA LEGITIMIDAD DEL INTERÉS DE GRUPO EN EL ORDENAMIENTO JURÍDICO ESPAÑOL
}

\author{
The legitimacy of the group interest \\ in spanish legislation
}

\author{
Lourdes Castro Crespo \\ Graduada en Derecho económico \\ Universidad de Deusto
}

http://dx.doi.org/10.18543/ed-69(2)-2021pp305-340

\section{Copyright}

Estudios de Deusto es una revista de acceso abierto, lo que significa que es de libre acceso en su integridad. Se permite su lectura, la búsqueda, descarga, distribución y reutilización legal en cualquier tipo de soporte sólo para fines no comerciales, sin la previa autorización del editor o el autor, siempre que la obra original sea debidamente citada y cualquier cambio en el original esté claramente indicado

Estudios de Deusto is an Open Access journal which means that it is free for full access, reading, search, download, distribution, and lawful reuse in any medium only for non-commercial purposes, without prior permission from the Publisher or the author; provided the original work is properly cited and any changes to the original are clearly indicated. 